\title{
MADERA Y OFICIOS DE LA MADERA EN BARCELONA. GUÍA DE FONDOS DEL ARCHIVO HISTÓRICO PARA SU ESTUDIO.
} WOOD AND WOOD TRADES IN BARCELONA. HISTORICAL FILE FUND GUIDE FOR ITS STUDY.

Àngels Busquets Relats* Arxiu Històric de la ciutat de Barcelona-Archivo Histórico de la ciudad de Barcelona (AHCB)

\section{Resumen}

La importancia de la madera como materia prima ha sido tal, que su elaboración y comercio por parte de los oficios que la trabajaban han sido objeto de regulación por parte de los gobiernos. Es el caso de Barcelona donde su gobierno autónomo, el Consell de Cent, dejó constancia de ello en diversas series de documentación municipal: ordenaciones, deliberaciones, libros del clavario, albaranes del racional o registros de obrería. Aparte del fondo municipal, el Archivo Histórico custodia fondos institucionales, privados- de entidades, personales y de empresas- y algunas colecciones facticias de documentación textual y gráfica. La guía que presentamos pretende dar una visión global de todos los oficios de la madera practicados en Barcelona, sus interrelaciones y sinergias con ámbitos tales como la construcción, la ingeniería o las artes decorativas. Nuestra comunicación coincide con la revisión técnica del fondo de la Cofradía de carpinteros consultable en línea (2020).

Palabras clave: carpinteros, toneleros, maestros de azuela, cajeros, luthiers, escultores.

\section{Abstract}

The importance of wood as feedstock has been such, that its trade and manipulation has been object of regulation by governments. The autonomous government of Barcelona, the Consell de Cent, kept a record of this regulation in the various types of municipal documentation: ordinances, deliberations, clavaris books, racionals dispatch notes and building registers. Not only does the AHCB hold these municipal archives, but also institutional and private documentation - personal and from entities and companies- in written and graphic collections. The guide here presented intends to give a global view on all the wood related trades developed in Barcelona, the interplay between them and their synergies whit other sectors like building, enginery, and decorative arts. Our communication coincides in 2020 with the technical revision done in the carpenter's guild documentary resource, available online (2020). 
Keywords: carpenters, coopers, adze master, furniture makers,luthiers, sculptors.

\section{1. Ámbito de estudio: la madera y los oficios de la madera.}

Dos premisas han guiado la configuración del presente estudio, elaborar una guía de fuentes del Archivo Histórico de la ciudad de Barcelona (AHCB), que facilite la búsqueda a los investigadores más allá de la mera enumeración, y enfocarla desde un punto de vista amplio dando a conocer documentación relativa al abastecimiento y comercio de la madera, a los carpinteros y todos aquellos oficios que en su trabajo tenían la madera como materia prima. Más allá de los carpinteros, nuestra guía ha tenido en cuenta los toneleros, los maestros de azuela, los cajeros, torneros, silleros de enea, escultores y constructores de instrumentos musicales.

También hemos puesto de manifiesto la importancia capital que los carpinteros tenían en la construcción y mantenimiento de edificios, de infraestructuras e ingenios.

Complementariamente hemos añadido a los pintores y doradores por su estrecha relación con los escultores y constructores de retablos.

\section{La imposición de la madera, un derecho de la ciudad.}

En la baja Edad media, Barcelona como capital del Principado de Catalunya, era un importante centro de poder político y económico bajo señorío real, y un centro naviero de primer orden. En la primera mitad del s.XV poseía dos atarazanas, las antiguas, de época condal, se remontaban al s.XI ${ }^{1}$, que ampliadas a mediados del s.XIII ${ }^{2}$ seguían activas a mediados del s.XV, y las atarazanas reales, que comenzadas a construir en el primer cuarto del s.XIV quedaron terminadas y ampliadas alrededor de 1420. Estos hechos sumados al desarrollo urbano implicaban que las necesidades lígneas de la ciudad fueran muy elevadas.

Barcelona se abastecía de madera en los bosques próximos a la ciudad, los del Vallés ${ }^{3}$, Maresme, Penedés o el Garraf, en otros más lejanos como el Montseny, el Montnegre, el Pirineo, Menorca o Aragó y cuando la demanda aumentaba por la construcción de escuadras navales se recurría a la importación. Entonces la Liguria, Croacia, Flandes, Castilla o el sur de Francia ${ }^{4}$ proveían importantes contingentes.

Sobre la madera pesaba eventualmente la prohibición de exportación. En 1241 Gregorio IX concedió a Mallorca comerciar con los estados islámicos exceptuando caballos, armas, hierro y madera ${ }^{5}$, una prohibición en la misma línea que la dictada en 1274 por Jaume I, de exportar a tierras del sultán de Alejandría ciertos productos entre los que también se encontraba la madera ${ }^{6}$ a fin de no facilitar al enemigo la construcción de barcos.

La lezda de Mediona, que en realidad era la lezda de Barcelona, grababa, desde finales del s. XII, en un 5\% la entrada y el paso por la ciudad de determinadas mercancías, entre ellas la madera ${ }^{7}$, pero también productos que viajaban en barriles, toneles o cubas como vino, harina o pescado seco. 


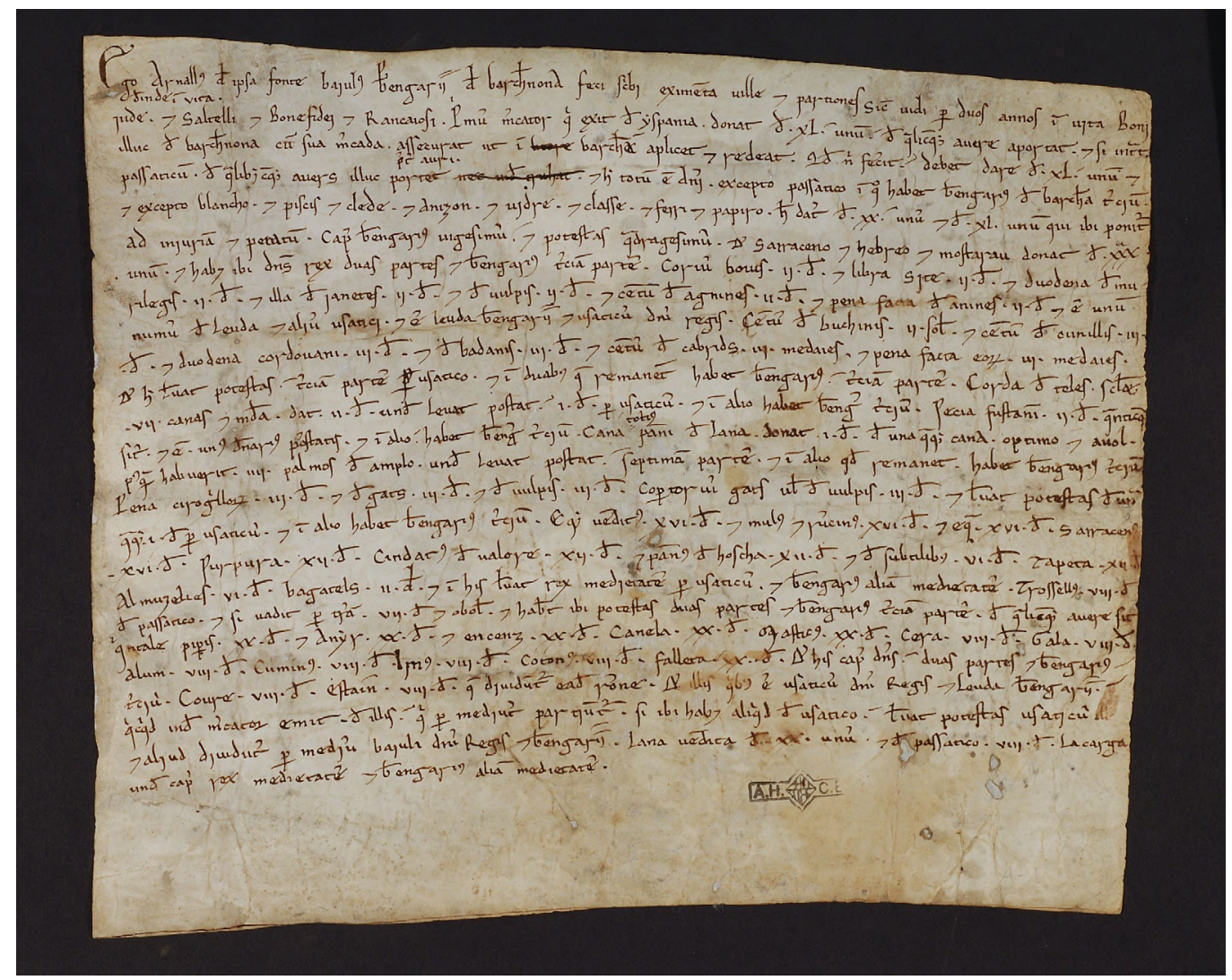

Fig. 1 Lezda de Mediona. Arnau Safont, baile de Barcelona hace constar por escrito las tarifas a abonar por las mercancías sujetas a la lezda de Barcelona y el reparto de ganancias de este impuesto entre el rey, al cual representa, y Berenguer de Mediona. 01/1A- 5 [1160- 1180]

Las imposiciones que Barcelona cobraba sobre la entrada, tránsito y pesaje de mercancías, eran unas dieciséis 8 . Eran gestionadas por diversos oficiales municipales: el clavario', el colector y el receptor de imposiciones, aunque su administración generalmente se subarrendaba a los llamados collidors de rendes. Su importancia queda reflejada en el siguiente dato: entre 1357 y 1361 el montante de dichas imposiciones suponía casi un 50\% de los ingresos municipales anuales y su importancia fue en aumento. Desde 1412, el presupuesto municipal se dividía en seis partidas de gastos, cada una de las cuales venía cubierta por el cobro de un paquete de imposiciones. En concreto, el paquete de impuestos sobre: cuero, madera, mantas, medio florín por tonel de vino y rentas de Flix, generaba un total de 1.800 libras destinadas a cubrir la partida de gastos correspondiente a obra pública ${ }^{10}$.

El estudio de las redes comerciales que operaban en el Mediterráneo y en las que participaban los puertos de Cataluña, Valencia y Mallorca ha puesto de manifiesto que en los siglos XIV y XV Valencia exportaba madera a Sicília, o que a mediados del s.XV los mercaderes catalanes mantenían un intenso comercio con Nápoles de dónde importaban madera, toneles y cercos de toneles ${ }^{11}$. La serie Miscel lània contiene noticias del comercio bajo medieval catalán en ultramar a través de los consulados, pero para conocer los cargamentos de época moderna conviene consultar la serie Reconeixements d'embarcaments, que contiene 
formularios especificando nombre y tipo de barco, nombres del patrón, consignatario y destinatario, puertos de salida y llegada y carga transportada, tanto en piezas de madera, como en mercancías contenidas en toneles o barriles. De forma complementaria conviene revisar el tráfico marítimo con los puertos de la Provenza, Liguria, Flandes, Valencia y Sevilla, a través del registro de entradas del puerto y las patentes de sanidad.

En el segundo cuarto del s. XVII existían oficiales de la ciudad con el nombre y cargo de proveedores, como el Carpintero proveedor de maderas, y en su nombre se efectuaban encargos y compras y se pagaban cuentas y giros. En la serie Registre de deliberacions. encontramos numerosas noticias de compra de material de construcción entre el que se encuentra madera destinada tanto a edificaciones como a construcción de navíos.

En cuanto a las variedades de la madera sabemos que, en lo tocante a construcción naval, la encina, el roble y el aliso se utilizaban para las partes que soportaban más tensiones, el pino, el álamo y el chopo servían para las cubiertas, y los abetos y pinos de más altura se utilizaban para los mástiles. El libro del Mostassaf o almotacén, registra ordenaciones fijando precios para las maderas de encina, roble, olivo, madroño y pino (1553). Establece una diferencia entre llenya-madera para construcción de edificios o naves, también llamados por extensión llenys o fustes-, y llenya menuda, leña menuda como brezo o sarmientos, destinada a quemar en el hogar o el horno.

El término llenya tenía antiguamente un sentido mucho más amplio, hoy su significado en catalán ha quedado restringido a la madera para quemar, y usamos genéricamente fusta. Nuestras búsquedas deben tener muy en cuenta ambos términos

Como ejemplo final para este capítulo hemos escogido el acuerdo entre los consellers y trece mercaderes para armar una nave de tres puentes contra los genoveses, que incluía en su cargamento toneles, barriles, cercos de barril de roble y avellano, tablas de madera de haya y maderamen sinnúmero (1331) ${ }^{12}$.

\section{Documentación a consultar:}

Fondos municipales: Consell de Cent i Ajuntament Modern-Consejo de Ciento y Ayuntamiento Moderno (CCAM)

- 01/IA Pergamins-Pergaminos. Consultables en línea, buscar los términos: lleuda y fusta-lezda y madera

- 01/1G-72 Llibre del mostassaf de Barcelona. Comprende ordenaciones de la leña que entra en la ciudad por tierra y mar, fols. 126-131r. y sobre las medidas del grueso, ancho y largo que deben tener las piezas de madera que se venden para la construcción, fol.25 bis r. (1396 y 1559).

- 06.01/1C.VI Imposicions-Imposiciones (1221-1714). Registros de los cobros de estas.

- 06.01/1B. XI Llibres de clavaria-Libros del clavario (1357-1699). Consignan las cantidades recibidas por los clavarios en concepto de cobros de las imposiciones.

- 02.01/1B. II Registre de deliberacions-Registros de deliberaciones (14331714). Consultar en los índices en linea: madera y leña. Los Vols.14, 36 y 62 
contienen noticias de talas y provisión de pinos y otras maderas, y de derechos sobre las mismas.

- 03/1B. IV Registre d'ordinacions-Registro de ordenaciones (1359-1714). En 1363 aparece la primera ordenación sobre compraventa de madera obrada o por obrar ${ }^{13}$.

- 03/1B.XXVI Ordinacions originals-Ordenaciones originales (1312-1714). Ordenaciones comunicadas a los ciudadanos por el pregonero de la ciudad. Incluye ordenaciones referentes a imposiciones en general y a la madera en particular.

- 02.01/1C Miscel lània-Miscelánea. Ver Vols. 7 a 9 (1268-1688).

- 12/1L.XII Recconeixements d'embarcaments-Reconocimientos de embarcos (1573-1911).

- 12/IL.X Entrada de vaixells al port-Entrada de barcos en el puerto (1719- 1834).

- 12/1L. XI Patents de sanitat-Patentes de sanidad (1508-1860).

AHCB2-281/FI-05-2A.4 Reial Junta de Comerç de Barcelona-Real Junta de Comercio de Barcelona. Consultar los índices en linea. Volúmenes (1749-1830): fusta; Cajas (1763-1836): madera.

\section{Noticias puntuales.}

- 03.01/1M Bans i altres impresos-Bandos y otros impresos. P.ej. Pregón 0186: Normativa sobre transporte de madera para la construcción de la Ciudadela (1721).

- 04/1B. IX Lletres reials originals-Cartas reales originales (1269-1714). Contienen alguna disposición sobre exenciones de impuestos a la madera.

- 11/1C.VII Armades i ports-Armadas y puertos (1334-1714) Docs. C.VII-22 a -24: factura por tala de árboles, inventarios de las atarazanas y relaciones de cargamentos de naves.

- AHCB2-421/FI-08.4 Arxiu Notarial-Archivo Notarial (1348-1862) la serie I Inventarios contiene el inventario de la casa-taller de un llenyater o tratante de maderas (1505).

\section{Los primeros oficios y cofradías de la madera en Barcelona ${ }^{14}$.}

Aunque es obvio que los oficios aparecieron antes de su regulación y antes de tener algún tipo de representación en el Consell de Cent, gobierno autónomo de Barcelona entre $1249^{15}$ y 1714 , una de las primeras formas de constatar la existencia más o menos consolidada de las corporaciones de oficios y su relevancia es comprobar su representación en el gobierno de la ciudad. Hay que recurrir al Llibre del Consell, serie primigenia, donde se registraron, entre 1301 y 1433, las elecciones y nombramientos anuales de los miembros del gobierno municipal: consellers, trentenari y Consell de Cent, así como deliberaciones, ordenaciones, correspondencia e incluso contabilidad. En cada volumen, después de la elección de los consellers, aparece la nómina de los cien jurados entre los que debemos buscar los que corresponden a los oficios de nuestro interés. 
En la tabla consta el número de representantes que los oficios de la madera tuvieron entre 1301-1399. Como la serie Llibre del Consell presenta algunas lagunas, los años que figuran corresponden estrictamente a aquellos de los que poseemos la nómina del gobierno y en los que además aparece el epígrafe de un oficio de la madera. El primero que se consigna son los toneleros, luego los cajeros y más adelante los carpinteros.

\begin{tabular}{|c|c|c|c|c|c|c|c|}
\hline $\begin{array}{l}\text { Llibre del } \\
\text { Consell }\end{array}$ & Toneleros & $\begin{array}{l}\text { Toneleros- } \\
\text { Cajeros }\end{array}$ & $\begin{array}{c}\text { Carpinteros } \\
\text { Toneleros }\end{array}$ & $\begin{array}{c}\text { Carpinteros- } \\
\text { Cajeros }\end{array}$ & Carpinteros & $\begin{array}{c}\text { Freneros- } \\
\text { silleros- } \\
\text { pintores }\end{array}$ & Freneros \\
\hline 1301 & 1 & & & & & 4 & \\
\hline 1302 & 1 & & & & & 4 & \\
\hline 1310 & 2 & & & & & 5 & \\
\hline 1312 & 3 & & & & & 3 & \\
\hline 1314- 1315 & 3 & & & & & 4 & \\
\hline 1316- 1317 & & 2 & & & & 2 & \\
\hline $1318-1319$ & 4 & & & 2 & & 5 & \\
\hline 1319- 1320 & 3 & & & 1 & & 5 & \\
\hline 1321- 1322 & 3 & & & & & 2 & \\
\hline 1323- 1324 & 2 & & & & & 4 & \\
\hline 1325- 1326 & 2 & & & & & 2 & \\
\hline 1326- 1327 & 3 & & & & & 6 & \\
\hline $1332-1333$ & 2 & & & & & 4 & \\
\hline 1333- 1334 & 2 & & & & & 3 & \\
\hline 1338- 1339 & 1 & & & & & & 1 \\
\hline 1340 & 1 & & & & & & 2 \\
\hline 1342- 1343 & 2 & & & & & & 3 \\
\hline $1345-1346$ & & & & & & & 2 \\
\hline 1350 & & & & & 2 & & 3 \\
\hline 1354 & & & & & & & 2 \\
\hline \multicolumn{8}{|l|}{1355} \\
\hline 1356 & & & 3 & & & & \\
\hline 1358 & & & 3 & & & & 2 \\
\hline $1360-1361$ & & & 3 & & & & 5 \\
\hline 1361- 1362 & & & 3 & & & & 5 \\
\hline 1362- 1363 & & & 3 & & & & 6 \\
\hline 1365- 1366 & & & 1 & & & & 5 \\
\hline 1366- 1367 & & & 4 & & & & 5 \\
\hline 1367- 1368 & & & & & 4 & & 5 \\
\hline 1373 & 2 & & & & 2 & & 5 \\
\hline 1374 & 1 & & & & 1 & & 2 \\
\hline 1375 & & & & & 3 & & 4 \\
\hline 1390 & & & & & 3 & & 4 \\
\hline 1391 & & & & & 4 & & 4 \\
\hline 1392- 1393 & & & & & 3 & & 3 \\
\hline 1395 & & & & & 2 & & 4 \\
\hline 1396 & & & & & 4 & & \\
\hline 1397 & 2 & & & & \begin{tabular}{|c|}
3 del Born 3 \\
C/Ample \\
\end{tabular} & & 4 \\
\hline 1399 & 2 & & & & 4 & & 4 \\
\hline
\end{tabular}

Tabla 1. Datos extraídos del Llibre del Consell-Libro del Consell 1B.I. Vols.1- 29 (1301- 1399). 
La tabla muestra que en ocasiones toneleros y carpinteros tuvieron representantes diferenciados bajo los dos epígrafes por separado y también que bajo un solo epígrafe doble se encontraban representantes de ambos.

Entre 1301-1343 el epígrafe: toneleros, es el primero que atestigua la representación en el gobierno de trabajadores de la madera. Entre 1345-1355 no hay representación de ningún oficio relacionado con dicha materia, excepto en 1350, en que bajo el epígrafe carpinteros, hay dos representantes, uno de ellos, tonelero: Bernat Riera i Guillem Brunet, boter. Entre 1356 y 1367 el doble epígrafe: carpinteros y toneleros, informa de la representación mixta de los dos oficios, y a partir de 1368 y hasta 1399 la representación está a nombre de los carpinteros en solitario.

Veamos las excepciones: en 1316 el epígrafe: toneleros se ha convertido en toneleros-cajeros, pero en 1318, los cajeros aparecen junto a los carpinteros. Sabiendo que los cajeros eran constructores de mobiliario debía tener más sentido su representación a través de los carpinteros que de los toneleros.

La segunda excepción, la representación por separado de toneleros y carpinteros, que se produce entre 1318- 1320 y entre 1373 y 1399, nos indica que aun cuando los toneleros habían desaparecido durante una década del epígrafe, posiblemente incluidos entre los carpinteros, en ocasiones pudieron optar a una representación propia.

Por lo que respecta a freneros y pintores, comentaremos los datos que nos aporta la tabla cuando hablemos de ellos más adelante.

Exponemos ahora una breve noticia de cada uno de los oficios de la madera que se desarrollaron en Barcelona a modo de marco contextual en el que presentar la documentación específica para su investigación.

\section{Boters, Barralers-Toneleros, Cuberos. Cofradía de San Juan Bautista degollado.}

Desde 1301 tuvieron representación en el gobierno de la ciudad, pero se constituyeron en cofradía bajo el patronazgo de San Jorge el 26 de mayo de $1456^{16}$ por un real privilegio de Juan de Navarra, lugarteniente de Cataluña. Aunque con anterioridad habían recibido ordenaciones puntuales ${ }^{17}$, en el momento de su constitución en cofradía se formalizó un articulado aprobado por los consellers ${ }^{18}$ susceptible de ser actualizado, completado o matizado con posterioridad.

La importancia de este oficio era obvia en las ciudades portuarias con alto volumen de exportación, pues los toneles, en todas sus variedades de capacidad eran el medio de transporte primordial y también un modo de dimensionar las naves por la cantidad de ellos que podían cargar: 1000, 1400, 1500, 2000 ${ }^{19}$.

Dentro del oficio existía una diferencia entre los que trabajaban la madera gruesa, boteri y la madera delgada, doleari. Solo los primeros podían construir aportaderas y cubas y sus litigios con los segundos fueron recurrentes hasta que firmaron una concordia a principios del s. XVI.

Existían capítulos dictados en $1446^{20}$ específicamente para los boteri sobre la elección de tres prohombres el día del santo patrón, la cuota de ingreso en la cofradía, la obligación de los aprendices de cumplir el período de prácticas y la sepultura de cofrades. 
Los doleari tenían también capítulos específicos de ordenaciones ${ }^{21}$, uno de 1481 regulaba la compraventa de madera para cubas de madera delgada, pues aparte de fabricar cubas y barriles, parece que elaboraban canastos, con listas entretejidas de madera muy delgada, que se usaban como envases alternativos a los toneles por ser mucho más ligeros.

Sin embargo, cuando la documentación menciona boters no se refiere estrictamente a boteri, sino que se trata del término genérico en catalán que los englobaba a todos. El oficio estuvo bajo la advocación de Sant Joan Degollaci, compatrono o patrono en substitución de San Jorge, y tenía su sede en el convento de la Merced, donde se celebraban conjuntamente los consejos generales, aunque boteri y doleari también celebraban consejos separadamente.

Ordenaciones posteriores a 1446 preveían que los patrones de naves comunicaran a los toneleros en general, a quien habían alquilado los toneles para evitar malentendidos en la recuperación de estos, especificaban con que madera debían construirse, indicaban que todos los toneleros debían compartir el suministro de esta y daban normas para su compraventa. Los precios de alquiler de cubas y toneles y la capacidad de estos también fueron objeto de regulación.

Por su estrecha vinculación con los patrones de barcos y los fletes, los toneleros solían trabajar en las mismas atarazanas o cerca de ellas, p.ej. los doleari vivían de antiguo en las Voltes de la mar $^{22}$ por autorización del veguer. Su vocabulario revela una curiosa identificación con el mundo de la dársena, pues cuando se referían a los toneles los llamaban botes $i$ altres vaxells, literalmente toneles y otros barcos. Vaixell, vexell o vaxell era el nombre de las cubas de más capacidad (actualmente 500-700 1.), y en orden de disminución seguía el mig vaixell (act. 200-500 1.). Para el transporte de vino se utilizaban botes, mitges botes, carretells (act. 30 l.) y quarteroles.

El Llibre del mostassaf o almotacén, funcionario que desde 1339 tenía a su cargo el control y la supervisión de la venta en los mercados, contiene numerosas ordenaciones concernientes al control de calidad de las botas de vino (vexells vinaris), aunque también aporta información sobre botas queseras, sardineras, arenqueras, atuneras, alumbreras o larderas. Para prevenir los fraudes este oficial actuaba en colaboración con los cónsules del oficio controlando que las cubas fueran de buena madera, que las dedicadas al vino no hubieran contenido otros productos y que todas ellas estuvieran marcadas adecuadamente ${ }^{23}$. 


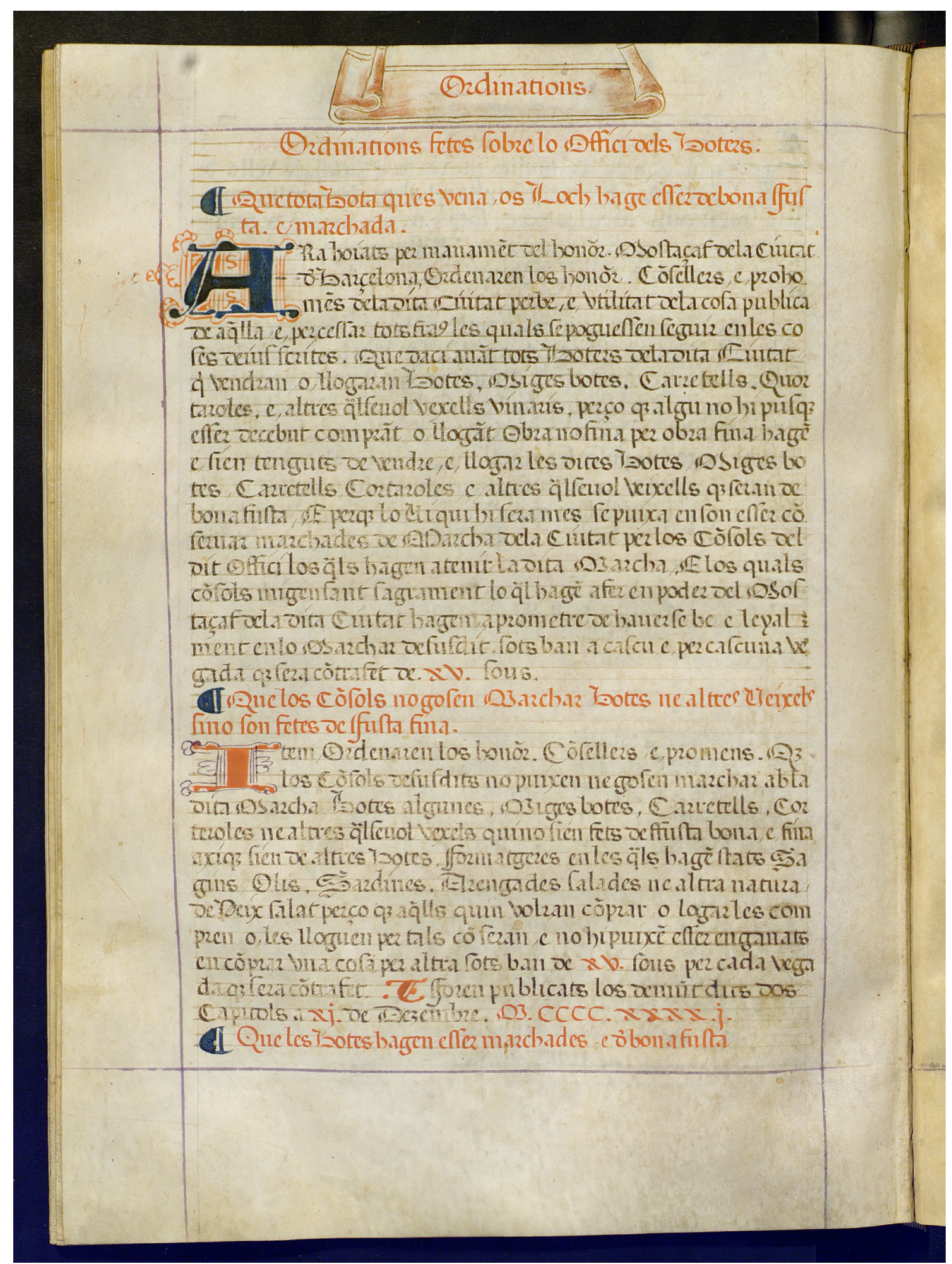

Fig. 2 Llibre del mostassaf. Ordenaciones de los toneleros. 01/1G-72, fol. 197v. (1339) 
Los toneleros no solo fabricaban piezas nuevas, reparaban las viejas y se ocupaban del mantenimiento de las usadas, pues de su buen estado dependía la conservación de los productos transportados: vino, carne adobada, aceite, alimentos secos y salados y, sobre todo, agua potable (barrils ayguaders), ya que transportaban no solo mercancías sino también los víveres para las tripulaciones ${ }^{24}$

Cuando las atarazanas reales de Barcelona fueron convertidas en maestranza de artillería (s. XVIII y XIX), los toneleros trabajaron también en la fabricación de armas y barriles para pólvora y proyectiles. La corporación pervivió cinco siglos y todavía en 1823, poco antes del decreto de disolución de los gremios (1828), encontramos a su corporación apelando a la Junta de Comercio.

\section{Documentación a consultar:}

\section{CCAM}

- 02.04/ 2A.2- C3 Boters-Toneleros (1442-1833), 23 docs.

- 02.04/ 2A.3- C1 Boters-Toneleros (1532), 1 doc.

- 02.01/ 1B.I Llibre del Consell-Libro del Consell (1301-1433)

- 02.01/1B. II Registre de deliberacions-Registro de deliberaciones (14331714). Noticias relativas a maestrías, ordenaciones y fabricación de barriles para pólvora. Consultar en los índices en línea los términos: toneleros, cuberos, barriles.

- 01/1G Manuscrits municipals-Manuscritos municipales. Ver 1G-38 Rúbrica d'ordinacions-Rubrica de ordenaciones, fol.185r.; 1G-72 Llibre del mostassaf de Barcelona-Libro del almotacén de Barcelona (1339-1691), fols.197v.-199v. y 1G-100 Rúbricas elaboradas por E. G. Bruniquer sobre la fundación y las ordenaciones de todas las cofradías de oficios.

- 03/1B. IV Registres d'ordinacions-Registros de ordenaciones (1359-1714): ver Vol. 5.

- 03/1B.XXVI-C3 Ordinacions originals-Ordenaciones originales (13121714). La primera ordenación publicada verbalmente relativa a barralers-cuberos es de 12.09.1433.

- 06.03/2A.5 Cadastre personal. Gremis-Catastro personal. Gremios (17161818): nóminas anuales de los miembros del gremio en activo. Buscar dentro de la $2^{\mathrm{a}}$ clase: cuberos.

- C.VII/24-4 Armades i port-Armadas y puerto. Ver los inventarios de la atarazana.

AHCB2-281/FI-05-2A.4 Reial Junta de Comerç de Barcelona-Real Junta de Comercio de Barcelona. Consultar índices en linea. Volúmenes (1749-1830): boters; Cajas (1763-1836): toneleros, cuberos.

AHCB2-421/FI-08.4 Arxiu Notarial-Archivo Notarial (1348-1862). Serie I Inventarios: algunos inventarios de toneleros, el primero de Pere Ferrer (1403). 


\section{Mestres d'aixa o fusters de ribera-Maestros de azuela o carpinteros de ribera. Cofradía de Santa Catalina y San Juan Bautista.}

Eran los constructores de navíos, los proyectaban, construían, reparaban y se encargaban de su mantenimiento. Tomaban el nombre de la herramienta que más les caracterizaba, la azuela, porque era la más adecuada para el trabajo de la madera curvada ${ }^{25}$. También eran constructores de carros y carretas y en este aspecto, derivaban directamente de los carpentari o constructores de carpenta (carros).

Se erigieron en cofradía, bajo invocación de Santa Catalina y San Juan Degollaci $^{26}$ por un real privilegio dado por Juan I en Sant Cugat del Vallès el 16 de septiembre de 1392. Sus capítulos fueron aprobados posteriormente por el rey Martí en 1400, recibiendo un nuevo privilegio del rey Ferran II (1493) y nuevas ordenaciones en 1488, 1616 y 1670.

Fue un oficio de primera magnitud en Barcelona, especialmente a raíz de la expansión marítima iniciada después de la conquista de Mallorca y hasta el s. XVI. Diversos estudios coinciden en constatar que en las ocasiones en que se debían armar escuadras los constructores no trabajaban solo en las atarazanas, donde obraban simultáneamente diez galeras o más, sino también en la playa, donde podían obrar otras tantas. ${ }^{27}$

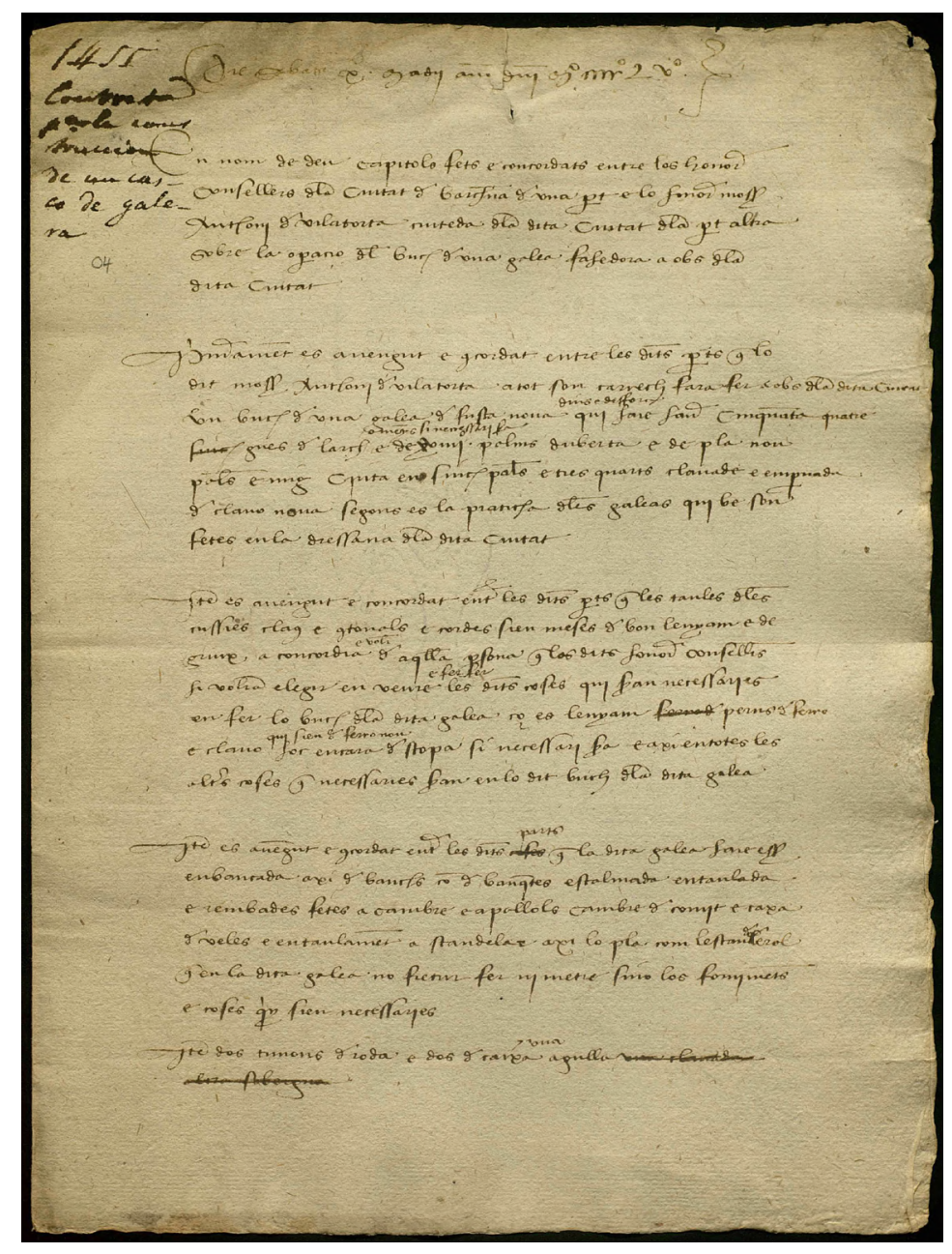

Fig. 3 Capítulos acordados entre los consellers y Antoni de Vilatorta para la construcción de una galera de la ciudad. 11/1C.VII22.06/4 (1455) 
Con ellos trabajaba toda una jerarquía de operarios especializados en la madera: mancebos de azuela, serradores y constructores de remos o remolars, a la vez que ellos mismos complementaban su trabajo con otras tareas de carpintería, por lo que deducimos que la divisoria entre los distintos oficios de la madera no era tan clara ${ }^{28}$.

Aunque el oficio no tuvo representación propia entre los cien jurados, sus ordenaciones deben buscarse entre los registros municipales, pues el Consell de Cent era la institución que tenía plena jurisdicción sobre todos los oficios de la ciudad, y, además, como ésta armaba naves propias, formalizaba contratos que encontramos mencionados en las deliberaciones y registrados en los protocolos notariales.

No tenemos conocimiento de un fondo documental producido por los maestros de azuela que se halle reunido en un archivo, por eso debemos acudir al Archivo de protocolos (AHPB) que custodia un volumen llamado Llibre de la confraria dels mestres d'aixa, al archivo del Museo marítimo de Barcelona (MMB) que conserva unas ordenaciones de los mismos a parte del fondo de la cofradia de Bastaixos i Macips de ribera (1346-1936), y al Archivo de la Corona de Aragón (ACA).

\section{Documentación a consultar:}

\section{CCAM}

- 02.04/2A.2-C17 Mestres d'aixa i calafats-Maestros de azuela y calafates, 15 docs. (1460-1830)

- 02.04/2A.2-C17 Mestres de carros $i$ cotxes-Maestros de carros y coches, 8 docs. (1761-1836)

- 03/1B.XXVI-C3 Ordinacions originals-Ordenaciones originales (1312-1714)

- 02.01/1B. II Registres de deliberacions- Registros de deliberaciones (14331714). Noticias relativas a construcción y reparación de naves de la ciudad. Consultar en los índices en línea: buques, galeotas, barcas, laúdes, galeras, goletas, construcción, maestros de aixa.

- 02.02/1B.XVI Corts i Parlaments-Cortes y Parlamentos (1350-1713). La demanda de construcción de naves queda reflejada en los donativos al rey pactados en las sesiones de Cortes, especialmente en los s. XIV- XV.

- 02.03/1I Consolat de mar-Consulado de mar (1347-1730) especialmente las series III, IV, VI i VIII contienen documentación relativa a construcción de naves y escuadras.

- 11/1C.VII Armades i port-Armadas y puerto (1342-1714). Destaca la unidad 1C.VII-22 (1455-1650) por contener una recopilación facticia de documentación de temática marítima y tipologías diversas: instrucciones para la construcción, compra de materiales, estimaciones de costos de construcción y contratos para la fábrica de embarcaciones.

- 06.03/2A.5 Cadastre personal. Gremis-Catastro personal. Gremios (17161818). Nóminas de miembros del gremio de Maestros de carros y coches en activo. Buscar dentro de la $2^{\text {a }}$ clase. 
AHCB2-421/FI-08.4 Arxiu Notarial-Archivo Notarial (1348-1862). Serie I Inventarios: de fabricantes de remos e inventarios de naves [1411-1458] Serie IX Contratos: construcción de naves (1451-1469).

AHCB2-281/FI-05-2A.4 Reial Junta de comerç de Barcelona-Real Junta de comercio de Barcelona Volúmenes (1749-1830) y Cajas (1763-1836). Ofrece escasas noticias. Consultar en los índices en linea: mestres d'aixa, fusters y carpinteros.

\section{Fusters-Carpinteros. Cofradía de San Juan Bautista y San José.}

Los carpinteros de Barcelona consideraban su oficio más antiguo que el diluvio universal puesto que entonces se había construido una gran arca, esto y la paternidad putativa de Jesús en la persona de su copatrono San José, formaban parte de su imaginario colectivo.

La primera mención bien documentada del oficio se remonta a $1318^{29}$ cuando, bajo el nombre de fusters $i$ caixers-carpinteros y cajeros, tenían dos representantes en el Consell de Cent. La diferenciación entre carpinteros y cajeros corresponde a la división que existía dentro del oficio entre carpinteros de la construcción y constructores de mobiliario que trataremos más adelante.

Una primera ordenación de 1334, muy genérica, les menciona trabajando con los obrers o encargados de las obras, tanto del común como de las parroquias y monasterios de la ciudad, y les advierte de no dejar madera fuera del ámbito de la obra, de no encender fuego bajo maderas levadizas y de no aserrar piezas arbóreas en ninguna otra calle que no sea la prevista para este uso, la calle de las tallas.

Se agrupaban en una zona de la ciudad muy cercana al mar, en las inmediaciones de la puerta de Regomir, justo donde se localizaban las primeras atarazanas situadas entre las actuales calles: Ample, de la Mercè, Avinyó y de la Fusteria. Esta ubicación atestigua el vínculo que el oficio tenía desde antiguo con la construcción naval. Como estas primeras atarazanas fueron ampliadas en dirección al Born, entre la calle Fusteria y el Pla de Palau, los talleres debieron extenderse también en esta dirección dando lugar a dos grupos conocidos como carpinteros del Born y del carrer Ample, ambos con representación en el Consell en 1397.

El privilegio real por el cual se constituyeron en cofradía, tomando a San Juan Degollaci por patrono, les fue dado por Joan I en el Monasterio de Valldonzella el 10 de abril de $1388^{30}$ y las ordenaciones por los consellers de la ciudad. A lo largo de los s.XV y XVI se añadieron capítulos sobre dónde emplazar los bancos de carpintería, prohibiciones como comprar madera fuera del circuito preestablecido o acumularla para luego revenderla, utilizar y vender madera en mal estado, verde o húmeda, o abrir tienda sin haber sido examinados. El articulado se completó derogando capítulos obsoletos y añadiendo otros nuevos acerca de respetar el ancho, grueso y largo de las piezas fijados por el afinador de pesos y medidas de la ciudad, la elección de prohombres, la realización de exámenes, etc.

Se regían por tres prohombres, un clavario, un receptor de los emolumentos y dos llevadors y se elegían, asimismo, cuatro examinadores y un síndico. 
Aparte de los consejos generales registrados en los libros de consells, los prohombres tenían sus reuniones registradas en los libros de pro[ho]menia.

Antes de 1397 utilizaron distintos espacios para la celebración de reuniones y consejos, en dicho año la catedral les cedió la casa del cabildo y a partir de 1511 hasta 1912 su casa gremial se situaba en la confluencia de la calle de la Fusteria con la Volta dels Encants ${ }^{31}$ o Voltes dels fusters. sede que abandonaron para trasladarse a la calle En Bot. Su sede religiosa era y es la capilla de San José en la catedral a la que se añadió, más adelante, una segunda capilla en el claustro de esta.

Desde antiguo los carpinteros barceloneses estaban divididos en dos cofradías separadas: ${ }^{32}$ fusters bosquers y fusters caxers. Los primeros derivaban de los sarcitector, en el sentido que los definen las Etimologías de San Isidoro: qui tecta facit, qui tecta resarcit. Obraban elementos esenciales en la construcción de edificios: pilares, columnas, cubiertas, techos, vigas, cerchas, montantes, puertas, y ventanas. En otros ámbitos geográficos eran conocidos como carpinteros de armar o de obra de afuera por trabajar fuera del taller o a pie de obra. Los sarcitector se oponían a los carpentari, conocidos como carreteros y, en ciertos ámbitos, como carpinteros de lo prieto para diferenciarse de los carpinteros de lo blanco, que, según define el Diccionario de la Real Academia de la lengua española, eran los que trabajaban en sus talleres haciendo mesas y bancos. Nuestros fusters caixers se corresponden con estos últimos y, al igual que ellos, realizaban mobiliario: cajas, bancos, sillas, armarios, arquimesas. En 1506 bosquers y caxers firmaron una concordia en virtud de la cual cualquier carpintero estaba capacitado para hacer ambos trabajos.

Apoyándose en los textos de Marco Vitruvio y en la literatura jurídica de B. Cassaneo o A. Calapino los carpinteros afirmaban en 1680, cuando sostuvieron el litigio contra los escultores, que eran arquitectos y que les eran propias: reglas, simetrías, ángulos y medidas geométricas. Dividían su trabajo en obra plana o feyna de pla y obra de arquitectura donde se incluía la escultura, que los carpinteros consideraban como propia. Coherentemente con esta concepción, en 1775 su clavario menciona la corporación con el nombre de gremio de carpinteros y arquitectos ${ }^{33}$

Su examen de maestría incluía la entrega de trazas de arquimesas, columnas, portaladas, cornisas, frontispicios de bies y montea y techos encabalgados ${ }^{34}$. Sin duda su trabajo implicaba conocimientos de geometría y trigonometría.

En su faceta constructiva los carpinteros cooperaban con los maestros de casas, tanto en la construcción de viviendas y obra privada, como en la construcción de edificaciones públicas: la casa del Común, la aduana, las atarazanas, la lonja, el estudio, los hospitales, la casa de la moneda, el amasadero o pastim, la pescadería, el faro de Montjuïc, la linterna del muelle, etc... Por este motivo, en ocasiones habían recibido ordenaciones conjuntamente ${ }^{35}$, pero la cooperación traía consigo el litigio puesto que eran profesiones rivales. Una sentencia determinó que los maestros de casas solo podían hacer los siguientes trabajos en madera: montaje de tablas, vigas y cabríos, y reparación de techos y terrazas ${ }^{36}$. Los carpinteros consideraban propio el cálculo de estructuras y construcción de estas.

Como las construcciones integrales en madera eran habituales, también lo era su mantenimiento. Los siguientes elementos o infraestructuras de carácter 
público estaban a cargo del Consell: las puertas y puentes de la muralla de la ciudad, el puente y la barca de Sant Boi y la barca del Prat, que eran los pasos principales sobre el rio Llobregat, los puentes sobre las acequias del llano de Barcelona y los barrancos de las faldas de Collserola, las norias de las huertas colindantes, fuertes, establos, cobertizos e incluso un tinglado para proteger la descarga de cereal que bajaba por el Ebro desde Flix, en la lejana Ribera de Ebro ${ }^{37}$.

La construcción y el mantenimiento eran motivo de continuos encargos por parte del gobierno de la ciudad y la causa de que existiera el cargo de carpintero del Común, que en 1446 era Pere Tarascó ayudado de otros oficiales y en 1477 Genís Caró. En 1635 fue Jaume Riera, teniendo como adjunto a Francesc Aymerich, el cual pasó a ser titular cuando Riera murió. Los carpinteros del Consell han sido identificados y estudiados, así como también sus obras ${ }^{38}$. Francesc Aymerich era autor, entre otras obras, de las puertas y bancos para la sala del Consell de Cent, así como de la linterna del muelle o del campanil donde sonaban las horas de la ciudad. La deliberación de 6 de septiembre de 1650 acuerda pagarle 200 libras por la factura de las puertas de dicha sala y otra de 17 de noviembre del mismo año acuerda pagar 15 libras al escultor Domingo Rovira por unos florones que decoraban dichas puertas. ${ }^{39}$

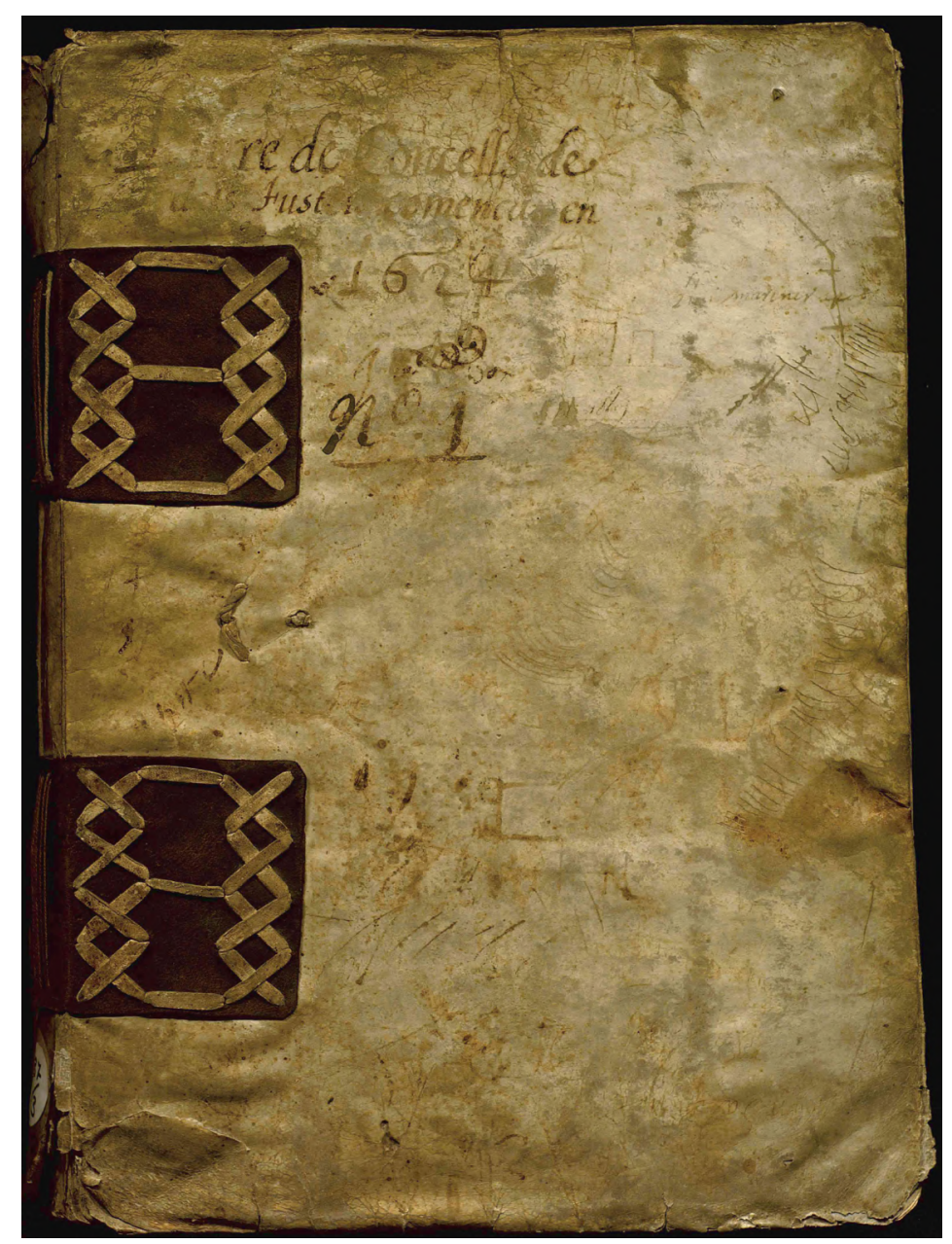

Fig. 4 Libro de consells de la Confraria dels Mestres Fusters. 5D142/003 (1624) 
Construcciones efímeras, como los puentes para el embarco y desembarco de autoridades o gradas y estructuras para actos públicos como justas o procesiones, corrían también a cargo del Consell ya que formaban parte de sus atribuciones protocolarias.

Los carpinteros mantuvieron dilatados litigios con los torneros, los escultores, los cajeros-torneros y los silleros de enea, todos ellos se escindieron de los carpinteros fundando sus propias cofradías. No deja de sorprender que incluso los encepadores y pedreñaleros, fueran examinados y licenciados por la cofradía de carpinteros.

Es interesante la mención que ellos mismos hacen de sus herramientas: escoplo, barrilete, garlopa, cartabón, acanalador, plomada, gubias, formones, mazas, azuelas, cepillos, planas, copadas, guillames, escuadras, niveles, y otras que omiten ${ }^{40}$.

El fondo más importante para consultar es el generado por la propia cofradía. Se halla en el AHCB desde 1948 y contiene privilegios fundacionales, ordenaciones, libros de consejos, nóminas de asociados, asientos de aprendices, libros de contabilidad del clavario y del receptor, entre los que destacan los de las cuotas o anyades, pleitos, documentación sobre maestrías, aprendizajes, mancebos, etc...

\section{Documentación a consultar:}

AHCB3-580/5D142 Fons de la Confraria de Sant Joan $i$ Sant Josep dels FustersFondo de la Cofradía de San Juan y San José de los carpinteros: 130 pergaminos (1330-1651), 71Vols. y 20Legs. (1583-1931). El Gremi de la fusta i del moble custodia algunas unidades documentales: el extraordinario Llibre de passanties (1778-1820)- que incluye dos documentos de 1876-, un Libro de privilegios y ordenaciones de 1750 y una libreta de cuentas de causas pías de 1894-1895.

\section{CCAM}

- 01/1G-38 Rúbriques d'ordinacions: resume el contenido de las sucesivas ordenaciones recibidas por los carpinteros entre 1334 y 1471.

- 02.01/ 1B.I Llibre del Consell-Libro del Consell (1301-1433): ver Vol.5 (1318)

- 02.01/1B.II Registre de deliberacions-Registros de deliberaciones (14331714). Numerosas noticias sobre obra pública, construcciones en madera y reparaciones a cargo del carpintero del común, salario y cuentas del carpintero. Consultar en los índices en línea: carpintero, carpintería, construcción, corrales, barracas, puentes, pontones, puertas, fuertes, garitas, celosías, ventanas, palenques. Como curiosidad constan unas obras de carpintería en el archivo del Consell de Cent: Vol.132 fols. 135 y 149 (1622).

- 03/1B.XXVI-C3 Ordinacions originals-Ordenaciones originales. La primera ordenación publicada verbalmente sobre carpinteros es de 05.05.1434.

- 03.1B. IV Registre d'ordinacions-Registro de ordenaciones (1359-1714)

- 02.04/2A.1-C5 Fusters i escultors-Carpinteros y escultores.10 docs. (1659-1711)

- 02.04/2A.2-C12 Fadrins fusters-Mancebos carpinteros 19 docs. (1730-1791)

- 02.04/2A.2-C12 y C13 Fusters-Carpinteros 268 docs. (1475-1845) 
- 02.04/2A.3-C2 Fusters - Carpinteros 8 docs. (1669-1818)

- 06.03/2A.5 Cadastre personal. Gremis-Catastro personal. Gremios (17161818). Constan las nóminas anuales de miembros del gremio en activo. Consultar las relaciones de $1^{a}$ clase, donde se refieren tanto los maestros como los mancebos carpinteros.

AHCB2-281/FI-05-2A.4 Reial Junta de comerç de Barcelona-Real Junta de comercio de Barcelona: Volúmenes (1749-1830) y Cajas (1763-1836). Ofrece noticias sobre maestros y mancebos carpinteros. Consultar en los índices en linea los términos: carpinteros y fusters.

AHCB2-421/FI-08.4 Arxiu Notarial-Archivo Notarial (1348-1862). Serie I Inventarios: inventarios de carpinteros y encantes anónimos que pueden ser de miembros del oficio. Serie IX Contratos: contratos de carpinteros (1420-1750).

\section{El papel de los carpinteros en las infraestructuras e ingenios}

Aparte de la construcción de edificios, los carpinteros también estaban presentes en la construcción de infraestructuras. Terminada la obra de las Atarazanas reales (1420) los esfuerzos de la ciudad se centraron en la construcción de una estructura portuaria al uso que la ciudad no poseía de forma natural ${ }^{41}$. El 2 de agosto de 1439 se puso la primera piedra para la construcción del primer muelle, previamente se había colocado una estacada de localización y se había depositado una caja que fue arrasada por un temporal en noviembre del mismo año. Debemos identificar dicha caja como un encofrado de madera que cargado de piedras y mortero de cal se hundía y hacía las veces de cimiento de la futura escollera. En la documentación municipal, caja, aparece también con relación a la muralla. La envergadura de infraestructuras como el muelle precisó de ayuda extranjera: las deliberaciones del Trentenari y Consell de Cent respectivamente de 25 y 26 de agosto de $1477^{42}$ tratan de la llegada del maestro siciliano Stasi Alexandrino. que con anterioridad había construido los muelles de Palermo y de Génova.

Junto con los cónsules de la mar visitaron la playa, sondearon la profundidad e hicieron las primeras valoraciones de la ubicación, coste de la obra, 15.000 ducados, y plazo de ejecución, tres años. También se trataron los honorarios del maestro que se cifraron en 30 ducados pagados sobre el dret de l'ancoratge o derecho de anclaje.

Si bien el término ingeniero no aparece en la documentación, sí aparece el d'enginy o ingenio en el sentido de solución mecánica o artefacto destinado a cumplir una función técnica: torsión, presión, contrapeso, arrastre... Como antes de la época industrial los ingenios se construían en madera, los carpinteros también eran constructores de ingenios. De nuevo, la documentación municipal consigna diversas noticias de ingenios construidos en madera y ocasionalmente reforzados con herrajes: las norias del Portal de Sant Antoni y dels Escorxadors, las acequias y canalizaciones de agua, los molinos de la ciudad -de viento o a tracción animal (molins de sang)-, molinetes de harina, molinetes de la ceca para batir moneda, árganos, cabrestantes, poleas y grúas usados tanto en las 
atarazanas como en la construcción. Las anillas que aún penden de los arcos de las Atarazanas reales de Barcelona permitían junto con los juegos de poleas izar y recuperar los barcos naufragados o maltrechos por los temporales.

Para terminar, un par de ejemplos: el Dietario menciona que el lunes 9 de agosto de 1593, el retablo del altar mayor de la catedral de Barcelona fue alzado seis palmos más alto de lo que estaba, con la ayuda de ingenios construidos por los carpinteros y maestros de casas. No satisfechos con el resultado, el 25 del mismo mes todavía alzaron el retablo un palmo y medio más ${ }^{43}$. Otro ejemplo son los dos molinetes destinados a batir moneda en la Ceca de la ciudad ${ }^{44}$ construidos por el carpintero del común, Francesc Aymeric, en 1641.

\section{Documentación a consultar:}

\section{CCAM}

- 02.01/1B. II Registre de deliberacions-Registros de deliberaciones (14331714): noticias sobre la construcción del muelle o puerto de Barcelona, atarazanas reales, aduana, lonja, lazareto, pastim o amasadero, estudio, plaza del Blat, linterna del puerto, casa de la moneda, ceca, molinetes, norias, etc...

- 11/1C.VII-18 Armades i ports-Armadas y puertos. Libro de pagos efectuados por el clavario en concepto de gastos por la construcción del muelle o puerto de Barcelona. Los inventarios de las Atarazanas pueden incluir ingenios.

- 03.1B. IV Registre d'ordinacions-Registro de ordenaciones (1359-1714). En el Vol.9 se encuentran ordenaciones comunes a carpinteros y maestros de casas.

- 02.04/2A.- C2 Arquitectes i mestres d'obres- Arquitectos y maestros de obras: presenta sólo 3 docs. (1728-1787).

- 02.04/ 2A.2- C15 Mestres de cases $i$ molers- Maestros de casas y moleros: 79 docs. (1455-1834) y Mestres de cases. Joves- Maestros de casas. Mancebos: 13 docs. (1650-1834).

AHCB2-421/FI-08.4 Arxiu Notarial-Archivo Notarial (1348-1862). Dentro de la serie IX Contratos encontramos algunos relativos a construcción de puentes (1461-1494).

AHCB3-384/5D32 Nissaga Fontserè. Fondo personal del carpintero y arquitecto Josep Fontserè i Domènech y de sus hijos Josep y Eduard Fontserè. (1805-1957).

\section{Caixers i torners- Cajeros y torneros. Cofradía de San Onofre.}

Ya hemos mencionado que los fusters caixers o cajeros, ocasionalmente designados como cofreros, se identificaban como constructores de mobiliario: mesas, bancos, arquibancos, cajas, baúles, arcones, arquillas, cajas tocador, cajas de novia, de reliquias, cofres y estuches para libros y documentos, cajas de barbero-cirujano para contener medicinas, ungüentos y material quirúrgico ${ }^{45}$, ataúdes, etc. 
A través del Libro del Consell hemos comprobado su existencia al menos desde 1316 cuando aparecen por primera vez unidos a los toneleros y, poco más tarde, en 1318, a los carpinteros. Su pertenencia a la cofradía de los carpinteros se mantuvo hasta 1556 fecha en la que los cajeros se segregaron para unirse, poco más tarde, en 1600 , a los torneros.

Por su parte, los torneros también eran una especialidad dentro de los carpinteros, con la particularidad que trabajaban la madera con el torno elaborando objetos y elementos decorativos como pomos, patas, columnas, etc... Probablemente colaboraron por igual con los escultores y con los fusters bosquers, obrando elementos arquitectónicos torneados tanto para retablos como para edificios. Se segregaron de los carpinteros en 1555 y recibieron ordenaciones propias este mismo año ${ }^{46}$.

Cajeros y torneros se unieron definitivamente en una cofradía bajo la advocación de San Onofre el 15 de enero de 1600, teniendo su sede en la iglesia de San Miguel. A partir de este momento se rigieron por ordenaciones comunes que, habiendo sido renovadas en 1645, estuvieron vigentes hasta el s. XIX. El gremio pervivió más allá del decreto de 1828.

Ambos oficios estuvieron relacionados con la fabricación de armas cuando las atarazanas reales se convirtieron en maestranza de artillería.

Antes de finalizar queremos mencionar dos piezas particulares: la caja de madera de ciprés con herrajes, destinada a contener las reliquias de Santa Eulalia, que en 1339 fue depositada en el sepulcro de mármol en la cripta de la catedral de Barcelona, donde todavía permanece ${ }^{47}$ y la caja de madera, también de ciprés, destinada a guardar una tela púrpura y una almohada que los consellers encargaron en diciembre de 1343 para las visitas de Pedro III a la ciudad. En ambos casos la madera de ciprés, perfumada y resistente a la humedad, fue elegida material noble acorde con el contenido ${ }^{48}$.

\section{Documentación a consultar:}

AHCB3-583/5D.145 Fons de la Confraria dels capsers $i$ torners-Fondo de la Cofradía de cajeros y torneros, 2vols. (1600-1646). El Vol.1 contiene el acto de unión de ambas cofradías (15.01.1600) y una propuesta de ordenaciones elevada al Consell dels 36 (22.10.1646). El Vol.2. es un Libro de consejos (1623) 


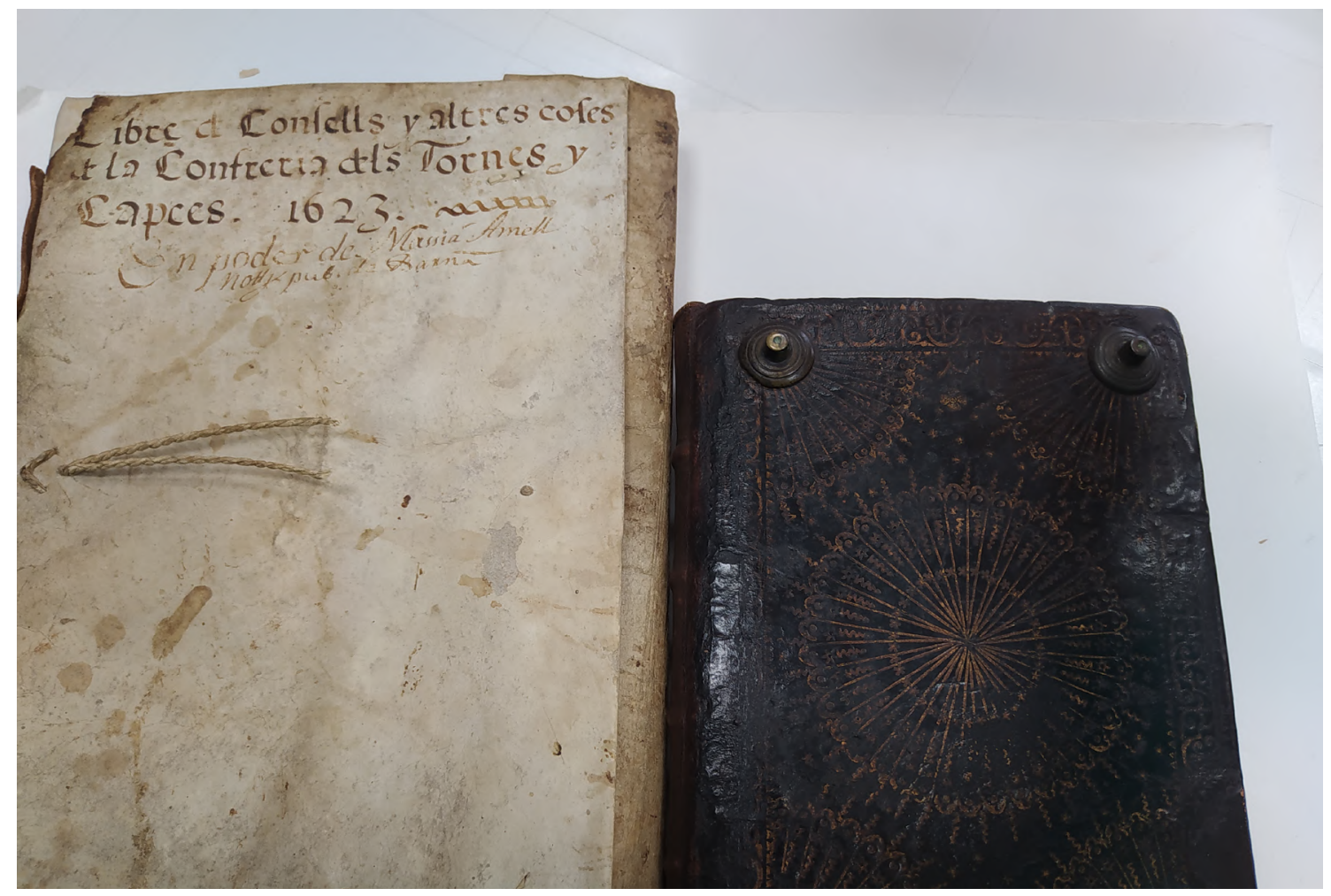

Fig. 5 Volúmenes de la Confraria de Capsers i torners 5D145/1 y /2 (1600 y 1623)

\section{CCAM:}

- 02.04/2A.2- C5 Capsers-Cajeros, 3 docs. (1601-1829).

- 02.04/2A.2- C25 Torners $i$ capsers-Torneros y cajeros, 21 docs. (1601-1833).

- 02.04/2A.3- C7 a C9 Torners i capsers-Torneros y cajeros, 7 docs. (1710-1815).

- 02.01/1B. II Registre de deliberacions-Registros de deliberaciones (14331714). Consultar en los índices en linea: torneros, cajeros, cajoneros, cajas, cofres, bancos, sillas, almohadones, arquillas, escribanías, mueblaje.

- 06.03/2A.5 Cadastre personal. Gremis-Catastro personal. Gremios (17161818). Son nóminas anuales de miembros del gremio en activo. Consultar $2^{\mathrm{a}}$ clase.

- 03/1B. IV Registres d'ordinacions-Registros de ordenaciones (1359-1714). Ver Vol 9.

- 09/1CXIV Obreria-Obrería (1351-1901). Es interesante consultar los planos de los palacetes del s. XVIII en el barrio de Sant Pere ya que consignan los nombres y uso de todas las estancias. Cabe remarcar que el estrado, espacio específicamente femenino está muy presente.

AHCB2-281/FI-05-2A.4 Reial Junta de comerç de Barcelona-Real Junta de comercio de Barcelona. Consultar índices en línia. Volúmenes (1749-1830): torners. Cajas (1763-1836): diversas notícias de cajeros y torneros por separado.

AHCB2-421/FI-08.4 Arxiu Notarial-Archivo Notarial (1348-1862) Serie I Inventarios: contiene inventarios de personajes de alto rango que pueden 
aportar noticias sobre mobiliario. P.ej: el de Joana, condesa de Foixà, infanta de Aragón, I.1-[1400]; el del cardenal Ferdinand Basilice, 1.12-(1402); el de Pedro de Portugal I.26-(1469); el de Joana Nicolaua, madre de Juana de Aragón, hija natural de Fernando II (1522), etc...

\section{Cadiraires de boga-Silleros de enea}

Hasta el momento de su constitución en gremio (1775), los silleros de enea, que no guardan relación con los silleros guarnicioneros, habían pertenecido a la cofradía y gremio de San Juan y San José de los carpinteros.

Diversos fabricantes de sillas de enea de la ciudad, encabezados por Mariano Roselló, elevaron a la Real Audiencia una instancia con una propuesta de ordenanzas solicitando constituirse en gremio. Ésta, pidió informe al Ayuntamiento de Barcelona, quien después de consultar a los carpinteros y torneros, aún con la oposición de los primeros, aconsejó la creación de este gremio por razones abiertamente proteccionistas, pues había un intenso comercio de importación de sillas de Holanda ${ }^{49}$. Finalmente, la corporación inició su andadura a partir de una real provisión y desde entonces una producción propia, cada vez más lujosa y sofisticada, tomó el relevo a dicha importación.

A partir de la creación del gremio, la documentación generada refleja dos hechos: la oposición de los cofrades a que siguieran existiendo los remendones de sillas que de forma ambulante trabajaban por la ciudad y la constatación de que "...las manufacturas se han alambicado a medida que se ha incrementado el lujo..." En este punto el mismo gremio advertía que la necesidad de compensar las cuotas de pertenencia a la asociación no debía incidir en un aumento de precio de las manufacturas locales haciéndolas más costosas que las extranjeras. Una vez expuesto el origen del gremio, queremos aprovechar este capítulo para desarrollar algunas reflexiones sobre los asientos en general. La traducción literal de cadira es silla, pero antes del s. XVIII no debemos interpretar el término en el sentido estricto que actualmente tiene, sino en un sentido amplio de asiento. El mismo trono de Martin el Humano recibe el nombre de la cadira del rei Martí.

La documentación municipal contiene numerosas noticias sobre asientos a partir del s. XV. Informan que aparte de ser objetos muebles eran símbolos del rango, dignidad y poder de quien los ocupaba. Existía una gradación de importancia protocolaria en los asientos que se asignaban a las autoridades en los actos oficiales. El rango máximo era el del rey y la reina que merecían cadires. Dado que eran para uso de grandes dignidades debemos pensar en asientos ceremoniales, dotados de respaldo, puede que también de brazos y probablemente labrados o decorados. La documentación menciona que algunos de ellos iban acompañados de cojines, sin especificar si su uso era para asiento, como escabel reposa-pies o reclinatorio, incluso se menciona a menudo que los asientos están dispuestos sobre una alfombra.

La cadira podía ser también un objeto ceremonial solemne usado a modo de facistol. Carlos de Viana, primogénito de Juan I reinante, juró el cargo de lugarteniente de su padre el rey, en la catedral de Barcelona, de rodillas sobre un cojín y apoyando ambas manos sobre un misal puesto delante suyo en 
un asiento cubierto con un sitial o paño de oro imperial. Enfrente el obispo de Barcelona sostenía en sus manos la Veracruz, que era adorada por el infante en la inclinación que hacía durante el juramento.

También los cinco consellers de Barcelona merecían asientos ceremoniales o cadires en todo tipo de actos civiles y religiosos. En su presencia solo podían sentarse en asientos semejantes los reyes, su lugarteniente y el obispo de Barcelona, no gozando del mismo derecho ni el regente, ni el canciller, ni los canónigos, ni los presbíteros de la catedral. Incluso delante de los representantes de la Junta de braços, reunidos en la Diputación del General en 1628, el conseller segon presidía la mesa de negociación desde la cabecera, sentado en una silla de terciopelo carmesí, en tanto que los demás miembros de la reunión ocupaban sillas de cuero ${ }^{50}$. El asiento inmediatamente inferior en rango era el escaño o el banco.

\section{Documentación a consultar:}

\section{CCAM}

- 02.04/ 2A.2-C4 Cadiraires-Silleros de enea (1775-1835): 35 docs. relativos a la constitución del gremio, maestrías, ordenaciones, cuotas...

- 08/1C.XXII Cerimonial-Ceremonial (1369-1714): noticias sobre el protocolo relativo a asientos (1562) y la silla real (1705).

- 02.01/1B. II Registre de deliberacions-Registros de deliberaciones (14331714). Consultar en los índices en linea: sillas, bancos, asientos.

AHCB2-281/FI-05-2A.4 Reial Junta de comerç de Barcelona-Real Junta de comercio de Barcelona. Consultar índices en línea. Volúmenes (1749-1830): cadiraires; Cajas (1763-1836): silleros de enea.

\section{Escultors-arquitectes i entalladors-Escultores-arquitectos y entalla- dores. Cofradía de los Santos mártires.}

Los escultores en madera, tallistas o imagineros se distinguían de los que trabajaban la piedra asociados a picapedreros y moleros. Los tallistas, que además de la madera solían trabajar el alabastro, se hallaban mayoritariamente incluidos en la cofradía de los carpinteros y eran examinados por los mismos. Por este motivo, no tuvieron representación directa en el gobierno de la ciudad. En 1605 resolvieron segregarse y constituirse en cofradía bajo la advocación de San Lucas. Aunque sucesivamente nombraron síndicos con atribuciones de clavario para encargarse de constituir la nueva cofradía y administrar la contribución voluntaria a los gastos ocasionados por la misma, pasaron 70 años sin que se consiguiera el objetivo. ${ }^{51}$ 

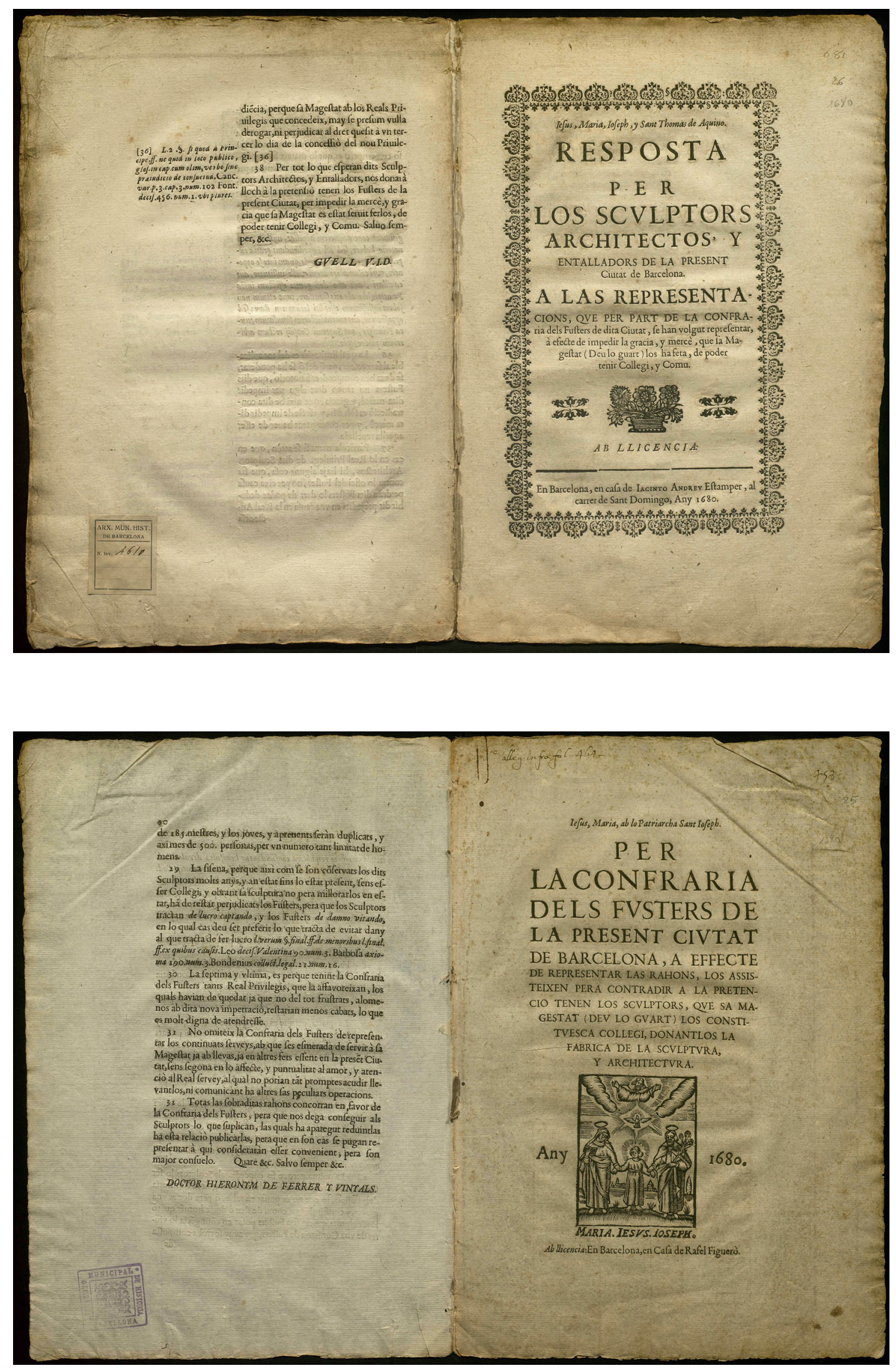

Figs. 6 y 7 Litigio entre Carpinteros y Escultores a raíz de la constitución de estos últimos en cofradía. 02.04/2A.1-C5 docs. 25 y 26 (1680) 
Ya antes de 1659 habían intentado delimitar su ámbito de acción respecto a los carpinteros, dilucidando cuales eran las atribuciones y trabajos propios de unos y otros. Parece que el de los escultores, arquitectos y entalladores estaba ceñido a la elaboración de: cornisas, columnas, frisos, arquitrabes, medios relieves, pilastras y pedestales ${ }^{52}$ y aparte todo tipo de imágenes de culto, así como retablos, sagrarios y tabernáculos. En 1675 reclamaban que se les reconociera la capacidad para hacer feyna de pla, es decir trabajo arquitectónico estructural, a lo cual se opusieron los carpinteros puesto que lo consideraban exclusivamente de su ámbito. Los escultores por su parte esgrimían que su arte no solo requería formación de geometría y aritmética, sino también conocimientos de historia y música y que trabajaban con las manos, pero tambien con el entendimiento.

En cuanto a las herramientas, aunque en carpinteros y escultores usaban las mismas, estos últimos manejaban una menor variedad: preferentemente gubias, formones, azuelas, la maza y el barrilete, por lo que los carpinteros no creían que ambos oficios debieran estar separados. Incluso bajo este prisma les parecía evidente la inclusión de la escultura dentro de la carpintería.

Sin embargo, la voluntad de los escultores de constituirse en corporación se mantuvo. En las deliberaciones del Consell de 17 agosto 1679 se estudió su memorial, se trató el tema de la constitución de su cofradía derivándose a una comisión de 4 miembros o quatrena del Consell de 36, y finalmente el 7 de septiembre de 1680 se publicaron las ordenanzas para la nueva corporación a pesar de la oposición de los carpinteros. Son interesantes las alegaciones esgrimidas en decenas de capítulos por unos y otros, las recusaciones e impugnaciones de los carpinteros incluso cuando los escultores ya habían obtenido el privilegio real otorgado por Carlos II el 7 de noviembre de 1680 por el que se constituían en Colegio de los Santos Mártires Escultores. Con la marcha de los escultores los carpinteros perdían la parte ornamental de la arquitectura y seguirían lidiando para conservar la arquitectura de estructuras que definitivamente acabaría formando parte de la nueva profesión de arquitecto.

Para terminar, un par de ejemplos: el 17 de agosto de 1456, los consellers adquirieron por 200 florines a un imaginero una imagen de Santa Eulalia, que fue colocada sobre el portal de la Davallada de la Cort (actual calle Llibreteria) en memoria del milagro de la santa en su primera traslación..$^{53} \mathrm{Y}$, en 1650, los escultores Aymerich y Roma presentaron las cuentas por sus trabajos en la Sala del Consell $5^{54}$.

\section{Documentación a consultar:}

\section{CCAM}

- 02.04/2A.1-C5 Fusters $i$ escultors-Carpinteros y escultores:10 docs. (16591711) Contiene los litigios habidos entre ambos oficios.

- 02.01/1B.II Registre de deliberacions-Registros de deliberaciones (14331714):ver Vol.188. Contiene la constitución de la cofradía y algunas noticias sobre escultores y encargos de imágenes. Consultar en los índices en línea: escultores, imagen. 
- 06.01/1B.XI Llibres de clavaria-Libros del clavario (1357-1699): constan los pagos efectuados por parte de los clavarios en concepto de obras realizadas.

AHCB3-580/5D142 Fons de la Confraria de Sant Joan i Sant Josep dels FustersFondo de la Cofradía de San Juan y San José de los carpinteros. 130 pergaminos (1330-1651), 71 Vols. y 14 Legs. (1583-1931). Consultar los pleitos con los escultores en los legajos 5D142/60, 64, 67 y 68.

AHCB2-421/FI-08.4 Arxiu Notarial-Archivo Notarial (1348-1862). Serie IX Contratos: contratos de escultores (1483-1749).

AHCB4-236/C06-Ms. B249 y -250 Oficis I (1880- 1940): Escultores, fols.148v169v. y Oficis II: Escultores, fols.1r-48v.

AHCB4-552/C22 Col lecció artistes catalans d'art gòtic inèdits-Colección de artistas catalanes de arte gótico inéditos. Mayoritariamente contiene contratos de encargo de piezas artísticas, convenidos entre obrers-obreros y representantes de parroquias y monasterios de Barcelona y maestros imagineros, pintores de retablos, etc.

\section{Pintors-Pintores. Cofradía de San Lucas.}

Pintores y doradores han sido incluidos en este estudio por su estrecha colaboración con los constructores de retablos y escultores.

Comentemos ahora los datos que presenta la tabla de la pág.8. Entre 1301-1334 los pintores aparecen asociados a freneros y silleros en un mismo epígrafe. Parece que, junto a los doradores, batihojas y guadamacileros formaban un grupo dentro de la cofradía de San Esteban, pero a partir de 1334 el epígrafe se reduce a freneros. El hecho de no ser nombrados no significa que no estuvieran incluidos, tanto más cuanto en los años siguientes el número de representantes oscila entre cuatro y seis, número que podría incluir representantes de diferentes grupos internos. Durante los s. XIV y XV los pintores se mantuvieron dentro del grupo de los freneros en tanto que los constructores de retablos debieron formar parte de la cofradía de carpinteros.

En cuanto a ordenaciones, resulta interesante el Ms. Mun.1G-38 Rúbrica d'ordinacions pues recoge como primera ordenación de los pintores una prohibición de 1296 relativa a no escribir ni pintar injurias sobre paredes ni tapias y la reiteración de esta en 1301 . Las ordenaciones de 1446, más explicitas, informan de que los pintores podían escoger dos cónsules propios que optaban al Consell, que estos debían jurar el cargo y denunciar los fraudes delante del mostassaf y que no podían tener taller propio sin haber sido examinados. Sus ordenaciones se completaron entre 1450 y $1505^{55}$.

También ellos se escindieron de la corporación que les había acogido, los freneros, y se constituyeron en cofradía en 1519. Recibieron el real privilegio de la reina Juana I de Catalunya-Aragó, el 30 de mayo de 1519 y eligieron la advocación de San Lucas, como en Italia, Países Bajos, Renania o Francia. Las ordenaciones que recibieron en este momento fundacional y que incluían las 
recibidas anteriormente, afectaban tanto a pintors cortiners-pintores cortineros como a pintors retaulers o retablistas es decir a los que pintaban sobre tela y sobre madera. ${ }^{56}$ En 1688 adquirieron el rango de Colegio.

Practicaban la pintura sobre madera y sobre tela, siendo autores de retablos y cuadros bien documentados y algunos conservados, todo tipo de insignias: banderas procesionales, estandartes, gonfalones, pendones de cofradías o banderines para instrumentos musicales. También pintaban sobre cuero, decorando sillas de montar y arneses, y sobre cristal, identificándose entonces como pintores de vidrieras.

La documentación municipal proporciona mucha información sobre los encargos que el común hizo a los pintores: la policromía de 1369 descubierta en 2017 en las vigas del patio gótico del Ayuntamiento de Barcelona es una buena muestra $^{57}$, pero también los encargos de retablos destinados a las capillas de la casa de la ciutat, la casa de las Egipciacas, las iglesias de S. Jaime, S. Sebastián, S. Justo y Pastor, Santa Madrona y obras sobre tela. Desde 1459 el Consell nombraba al menos un pintor oficial a su servicio ${ }^{58}$. Las Rúbriques de Bruniquer proporcionan no menos de ciento veinte noticias relativas a construcción y pintura de retablos y encargo de cuadros. Son un buen punto de partida para localizar los encargos de obras en los Libros de deliberaciones del Consell y los posteriores pagos en los libros de cuentas del clavario.

Para terminar, la mención de dos documentos. En una deliberación de 30 de noviembre de 1663 el Consell resuelve pagar 35 libras al pintor Abdó Ricard por la fábrica del cuadro de Santa Madrona, se trata de la pintura en la que aparece el conseller Rafael Bonaventura de Gualbes junto a Santa Madrona, de la que no se tenía constancia de ningún documento que acreditara que fue un encargo del gobierno de la ciudad. ${ }^{59} \mathrm{El}$ segundo es la deliberación de 1581 en que el Consell acuerda pagar 190 libras a los pintores Anthoni Torenoy y Benet Gallendo por pintar la bandera de tafetán carmesí que debía ir en las procesiones, la bandera de Santa Eulalia. ${ }^{60}$

\section{Documentación para consultar:}

\section{CCAM}

AHCB3-581/5D143 Fons de la Confraria de Sant Lluc dels pintors-Fondo de la Cofradía de San Lucas de los pintores (1519-1773), 2 Vols.: un libro de ordenaciones de la cofradía de pintores retablistas (1686) y un libro de privilegios y ordenaciones del Colegio de pintores de Barcelona.

- 02.01/1B. II Registre de deliberacions-Registro de deliberaciones (14331714). Más de 250 noticias sobre pintura y encargos de retablos, cuadros y vidrieras. Consultar índices en línea.

- 03/1B. IV Registre d'ordinacions-Registro de ordenaciones. (1359-1714): ver Vols.7, 23, etc...

- 06.01/1B. XI Llibres de clavaria-Libros del clavario (1357-1699). Constan pagos efectuados por los clavarios en concepto de obra realizada.

- 03/1B. V Ordinacions especials-Ordenaciones especiales (1349-1569) 
- 08/1C.XXII-1/42 Cerimonial-Ceremonial. (1369-1713) 3 docs.

- 02.04/2A.1-C8 Pintors-Pintors, 1 doc. (1700).

- 02.04/ 2A.2-C20 Pintors-Pintores (1453-1818), 24 docs.

AHCB2-281/FI-05-2A.4 Reial junta de comerç de Barcelona-Real junta de comercio de Barcelona. Volúmenes (1749-1830): noticias de pintores de tejidos y seda; Cajas (1763-1836): noticias de pintores de vidrieras.

AHCB4-552/C22 Col lecció artistes catalans d'art gòtic inèdits-Colección de artistas catalanes de arte gótico inéditos.

AHCB4-422/C19 Divulgació històrica de Barcelona-Divulgación histórica de Barcelona. Artículos sobre pintores de diversos autores: Verrié, Alcolea, Garrut, Madurell y Sobrequés.

AHCB2-421/FI-08.4 Arxiu Notarial-Archivo Notarial (1348-1862). Serie IX Contratos: contratos de pintores (1390-1629).

AHCB3-284/5D06 Fons Josep Arrau Barba-Fondo Josep Arrau Barba. Fondo personal del pintor. Contiene memorias entre 1834 y 1866 sobre historia del arte, técnicas artísticas etc...

\section{Dauradors, estofadors, esgrafiadors i encarnadors-Doradores, esto- fadores, esgrafiadores y encarnadores. Cofradía de San Lucas.}

Bruniquer en su rúbrica de cofradías (1G-100) expresa con toda certeza que los doradores recibían el nombre de pintors retaulers o pintores retablistas para diferenciarlos de los pintors cortiners ${ }^{61}$ o pintores cortineros. Así pues, en origen los doradores eran indisociables de los pintores. Ambos habían encontrado su representación en el Consell a través de los freneros y se separaron de ellos constituyéndose en la Cofradía de San Lucas en 1519, pero parece bastante más difícil precisar la fecha en que los doradores se segregaron de los pintores. Se ha sugerido entre 1640 y 1682 y de nuevo Bruniquer consigna que la cofradía de los doradores fue erigida y creada por los consellers el 1 de febrero de 1650. Las noticias pueden parecer desconcertantes: en 1649 doradores y estofadores recibieron ordenaciones propias ${ }^{62}$ mientras que en 1665 recibían otras comunes con los pintores; los doradores formaban parte del Colegio de pintores erigido en 1688, como lo confirma un doble litigio de 1703 seguido en la Real Audiencia y en el Consell de Cent por el pintor Josep Vives contra el Colegio de doradores, pintores y retablistas, pero las ordenaciones eran claras al respecto, ningún pintor, aún examinado, podía aceptar trabajos de dorado o estofado y viceversa. Todos estos datos sugieren un cierto grado de unión que coexistía con cierto grado de independencia. Compartían la advocación de San Lucas, pero los doradores elegían a sus propios representantes en número de dos y ya en el s. XVIII pintores y doradores contribuyeron al catastro separadamente. Al igual que los escultores, no tenían representación directa en el Consell de Cent. 
Las deliberaciones del gobierno de la ciudad reflejan diversas cuentas por compra de material y muestran una vez más a los artesanos doradores trabajando en obras tan diversas como retablos para las Capillas de San Sebastián y Nuestra Señora de la Canal, una imagen de Santa Eulalia, el dorado de varas y pomos de palios procesionales o el dorado y pintura efectuados en la Casa del Consell, etc.

El fondo de la cofradía que posee el AHCB no siendo excesivamente extenso contiene documentación muy valiosa: dos legajos de (1703-1834) y (1751-1833) y 142 trazas presentadas como exámenes de maestría de 1695 en adelante.

El documento ilustrativo es el acuerdo que resolvía pagar en diversos términos un total de 790 libras a los doradores Joan Niberto y Josep Massana en pago del contrato para dorar, encarnar, estofar y dar color a diversas figuras de la sala del Consell de Cent ${ }^{63}$.
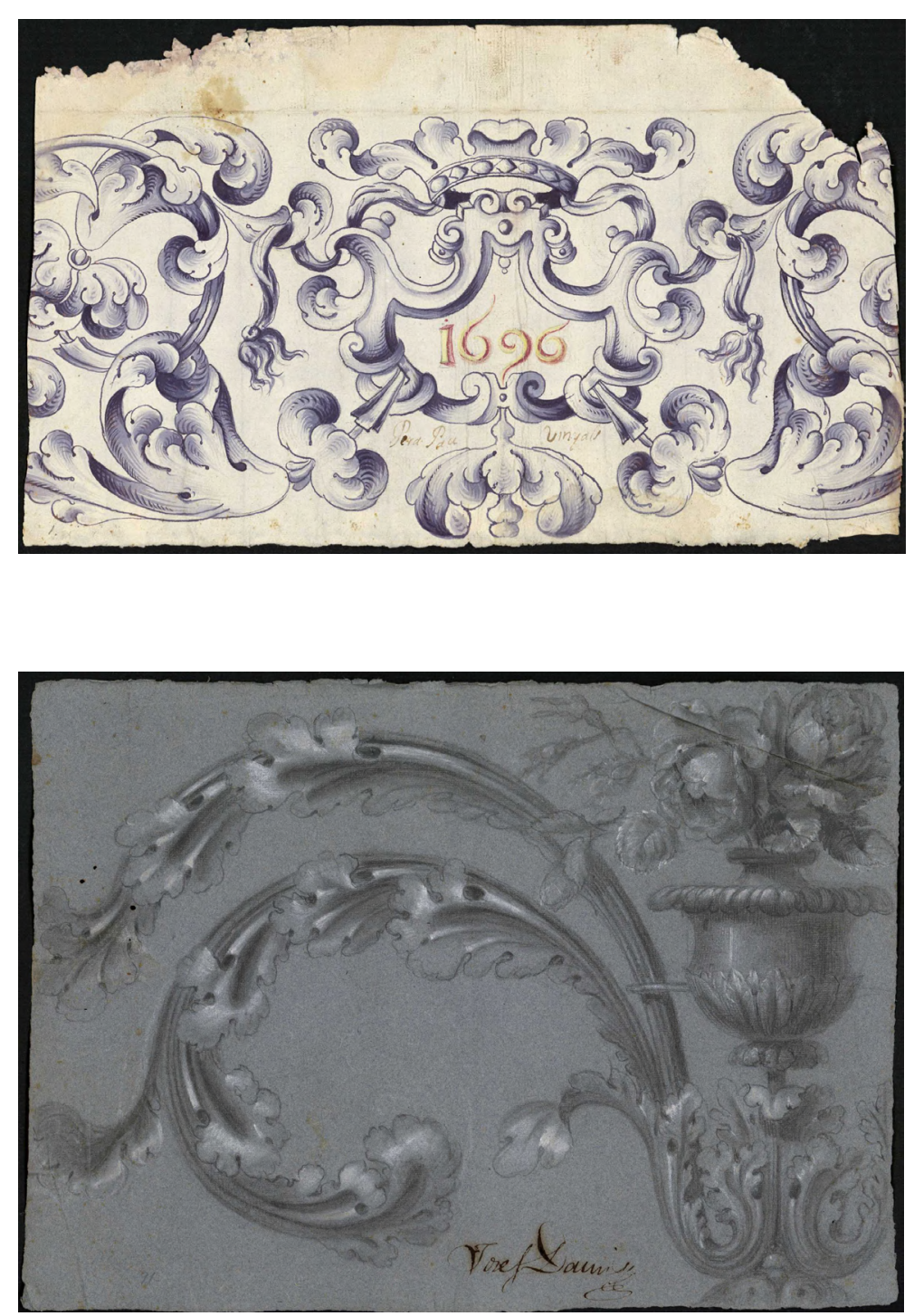

Fig. 8 y 9 Trazas efectuadas como exámenes de maestría del fondo de la Confraria dels Dauradors AHCB3-582/5D.144-3 docs. 1 y 91 (1696 y s.d.) 


\section{Documentación para consultar:}

AHCB3-582/5D144 Confraria dels dauradors-Cofradía de doradores (17031834), 243UD.

\section{CCAM}

- 02.01/1B.IIRegistre de deliberacions-Registro de deliberaciones (1433-1714). Consultar en los índices en linea: doradores, estofadores.

- 03/1B. IV Registre d'ordinacions-Registro de ordenaciones. (1359-1714).

- 02.04/2A.1-C4 Dauradors-Doradores, 1 doc. (1780): ordenanzas de la hermandad del gremio de doradores.

- 02.04/ 2A.2-C9 Dauradors, estofadors, esgrafiadors i encarnadors-Doradores, estofadores, esgrafiadores y encarnadores (1782-1820), 42 docs.

- 06.03/2A.5 Cadastre personal. Gremis-Catastro personal. Gremios (17161818). Nóminas anuales de miembros en activo entre 1775 y 1818 . Consultar la $3^{\mathrm{a}}$ clase.

AHCB2-281/FI-05-2A.4 Reial junta de comerç de Barcelona-Real junta de comercio de Barcelona Consultar índices en linea. Volúmenes (1749-1830): dauradors; Cajas (1763- 1836): doradores.

AHCB4-552/C22 Col lecció d'artistes catalans d'art gòtic inèdits-Colección de artistas catalanes de arte gótico inéditos.

AHCB4-236/C06-Ms. B298 Oficis I (1880- 1940): Doradores, fols 84v a 146v.

AHCB4-422/C19 Divulgació històrica de Barcelona-Divulgación histórica de Barcelona. Dos artículos de Josep M. Garrut sobre el esgrafiado.

\section{Violers, guitarrers, orgueners $i$ corders de viola-Constructores de vihuelas, guitarras, órganos y fabricantes de cuerdas de tripa}

Trabajaban la madera no solo artísticamente sino también bajo rigurosos parámetros que condicionaban la precisión y calidad del sonido.

Aunque poseemos escasas noticias de la construcción de instrumentos en Barcelona entre los s. XIV y XVII, las series de inventarios y contratos del Archivo Notarial aportan algunas noticias relativas a instrumentos de cuerda frotada, pulsada y de tecla, sobre todo violes, guitarras y órganos. Un buen ejemplo es el inventario post mortem de la vivienda y taller-tienda de Bartomeu Joan, violer, situado en el Born en $1495^{64}$. Consigna una caja-aparador con más de veinte violes construidas y aptas para sonar, aunque sin cuerdas ni clavillas, otras en construcción, algunas viejas desencordadas, multitud de tapas y cajas (armónicas), mástiles, numerosos bancos de trabajo, abundantes herramientas como limas, un barreno, una doladera, aros de madera, moldes y maderas varias de pino, de ciprés o de álamo. No podemos deducir si dichas violes se tocaban con plectro o con arco y por consiguiente si eran vihuelas de mano y de 
péñola o si pertenecían a la familia de las violas da bracchio y da gamba. Lo cierto es que la existencia y extraordinaria riqueza de este inventario atestigua fehacientemente la construcción, compraventa y reparación de uno de los principales instrumentos de cuerda del renacimiento.



Fig. 10 Inventario de Bartomeu Joan, violer (1495). AHCB2-421/FI-08.4/ 1-18 
Los registros de deliberaciones proporcionan alrededor de unas 90 entradas que certifican una actividad musical regular en forma de capillas ${ }^{65}$, la de la catedral, las de numerosas iglesias y la de la Casa de la ciutat, con la consiguiente formación, exámenes, oposiciones a las plazas, salarios, etc, así como la existencia de un maestro de música y un cap mestre o primer maestro de trompetas del Consell. Se consigna actividad musical en oficios religiosos y procesiones, actos protocolarios, victorias militares, celebraciones de nacimientos, esponsales, en los inventarios de las tres series de protocolo: 1D.XXI Protocol, 1C.XXII Cerimonial y 1B.XXV Dietari de l'antic Consell barceloni y sabemos de la existencia de dos cofradías de músicos, la de los ministriles, instituída en 1592 por Felipe II bajo la advocación de Santa Cecilia en la iglesia del Carmen, que acogía instrumentistas de "violes d'archs, violons, arpes, rebequets, gaites i tambors de cordes" y la cofradía de San Bernardo que acogía a los trompetas, trompistas, sonadores y otros juglares.

La regulación de la venta de tripa a los fabricantes de cuerdas o corders de viola está muy documentada en las ordenaciones, siendo la principal norma que respetar el que la tripa debía ser comprada directamente en el maell $o$ matadero.

Nuestro documento ilustrativo es de 1670 y está relacionado con la actividad musical en la Casa de la ciutat. Jaume Henrich, maestro de violín, suplica a los consellers que la plaza que ocupa y a la que debe renunciar por falta de salud, sea dada a Francesc Benet mediante la oposición correspondiente ${ }^{66}$.

Posteriormente, en los s. XIX y XX, está documentada la construcción y venta de instrumentos de música en Barcelona: pianos, pianolas, órganos y harmoniums, por lo que aportamos algunas referencias, en este caso de tipo gráfico.

\section{Documentación para consultar:}

\section{CCAM}

- 02.04/2A.2- C7 Corders de viola-Fabricantes de cuerdas de vihuela: 32 docs. (1458-1834).

- 02.01/1B. II Registre de deliberacions-Registro de deliberaciones (14331714). Consultar en los índices en linea: música, ministriles, trompeta, tabal, tambor, violín.

AHCB2-421/FI-08.4 Arxiu Notarial-Archivo Notarial (1348-1862). Serie I Inventarios (I.18): diversos inventarios de constructores de instrumentos y fabricantes de cuerdas. Serie IX Contratos: contratos de orgueners-constructores de órganos (1420-1632).

AHCB2-281/FI-05-2A.4 Reial junta de comerç de Barcelona-Real junta de comercio de Barcelona. Volúmenes (1749-1830); Cajas (1763-1836). Consultar en los índices en línea los términos: guitarrers, vihuela y músicos.

Ver entre la documentación gráfica la propaganda comercial de fábricas de piano como Bernareggi, Ortiz y Cusó, Maristany, etc... 


\section{FONDOS PRIVADOS PERSONALES DEL AHCB}

- AHCB3-296/5D38 Miquel González i Sugrañes. Estudioso de los oficios de Barcelona, su fondo guarda el trabajo preparatorio y el borrador de una monografîa sobre los carpinteros de Barcelona que nunca llegó a publicarse. 5S38/C3 leg. 3.

- AHCB3-286/5D.08 Antoni Aymar i Puig. Fondo del autor de la reseña histórica sobre los carpinteros barceloneses promovida por la misma cofradía y editada por La hormiga de oro en 1906.

- AHCB3-260/5D16 Francesc Carreras Candi. El fondo contiene las notas utilizadas para la edición de la Geografía de Catalunya.

- AHCB3-291/5D.23 Alfons Damians: varios legajos relativos a cofradías, gremios y hermandades.

- AHCB3-089/5D49 Josep Mas i Domènec (Mn. Mas): noticias sobre pintores del s. XIV-XVIII, escultores, doradores, pinturas, cuadros y retablos, puertas y portales.

- AHCB3-375/5D22 Francesc Curet i Payrot: dossieres y pliegos sobre oficios, gremios y artes, y mundo corporativo.

\section{DOCUMENTACIÓN GRÁFICA}

AHCB4-203/C03 Col lecció de Dibuixos-Colección de Dibujos.

- C03.02 Artes decorativas. Diseños para la estampación de indianas: AHCB 19341 a AHCB 19581 (240 UD-Indianes C1-1 y C1-2) AHCB 19582 a AHCB 19660 (78 UD- F4-C1, 49.2-1 y 50.1-C2)

- C03.03 Dibujos de temática barcelonesa:

AHCB 01719 Mueble de ángulo en la casa familiar de Alexandre de Riquer. 1887

AHCB 03542, 03815, 03816 Proyectos de mobiliario para la Casa Gran o Ayuntamiento de Barcelona.

AHCB 10452 (1-7). Proyectos de Agustí Rigalt, Ejercicios de oposiciones de 1876 entre los que hay tres de carpintería "Aparador para el comedor de un palacio"

AHCB4-204/C04 Col lecció de gravats-Colección de grabados:

- Figurines editados en París, Colección perteneciente al Fons Agustí Massana-AHCB3-234/5D12 Journal des demoiselles, Les Modes parisines, Le Moniteur de la mode, Le salon de la mode, La mode, Le cabinet de lecture, El correo de ultramar, le Lion o el Petit Courier des dames. Presentación de la moda acompañada de mobiliario, aunque por ser ediciones francesas se trata de mobiliario francés.

AHCB4-205/C05 Col lecció de cartells-Colección de carteles:

- Los correspondientes a l'Exposició Internacional del moble i decoració d'interiors- Exposición Internacional del mueble y decoración de interiores, Barcelona (1923). 30199-31202.

- Escultors a l'Escola Massana. Exposició a la capella (1991). 33238 
AHCB4-326/C14 Catàlegs d'exposicions-Catálogos de exposiciones. Pintores y escultores s.XX:

- Faianç Català 1913/ Galeries Laietanes 1916-1954/ Galería Parés 19291983/ Syra 1935- 1941/ Sala Fortuny 1936/ Sala Gaspar 1941/Vinçon 1943/ Sala Rovira 1947/ Circol Artístic de St.Lluc 1962/ Foga 2 1977/ Sala Nike 1977/ Caixa de Barcelona 1979/ Theo 1988.

\section{C16 Col·lecció Ephemera}

- C16.01 Targetes publicitàries-Tarjetas publicitarias de establecimientos dedicados a mobiliario, ebanistería, ebanistería americana, silleros, tapiceros, torneros, adornistas, etc. AHCB C16.01-24. S y C16.01-25 (p. Ej: 26759, 26850, 26853, 26856, 26858, 26860, 26861, 27195).

- Propaganda comercial. Catálogos de fábricas barcelonesas de pianos, órganos, harmoniums: Al violín de oro (Pi-1/5), Bernareggi (Pi-1/8), Guarro (Pi1/11), Ortiz i Cusó (Pi-1/14).

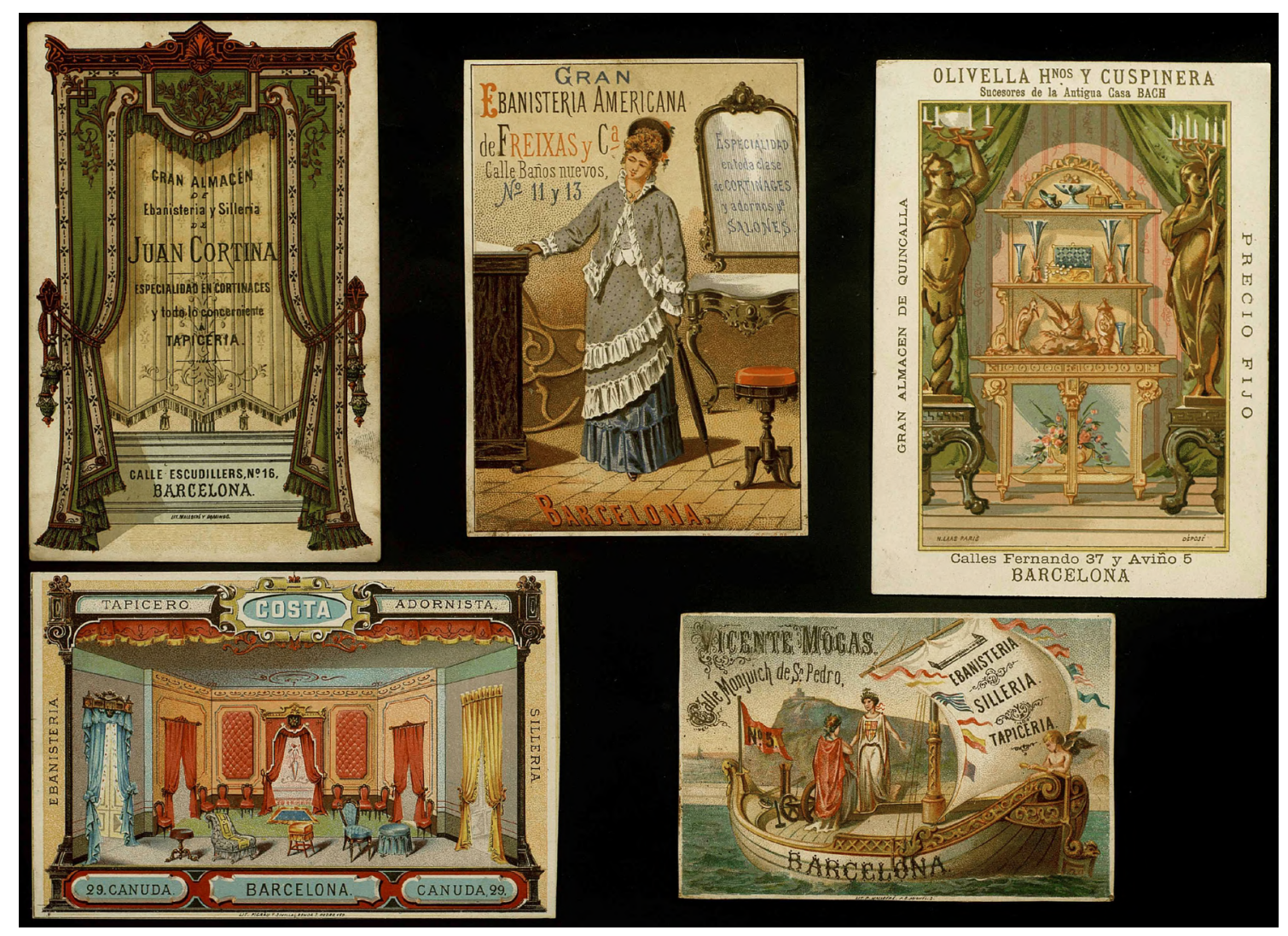

Fig.11 Ephemera.Tarjetas publicitarias: AHCB4-347/C16.01/26859, /26850, /26759, /27195, /26854 (ca. 1850). 


\section{NOTAS}

${ }^{1}$ Marcel Pujol, "Tecnología marítima en la corona de Aragón. Construcción naval, navegación e infraestructuras portuarias," en Ars mechanicae: ingeniería medieval en España (Madrid: Fundación Juanelo Turriano, 2008), 165.

${ }^{2}$ Albert Estrada Rius, La Drassana reial de Barcelona a l'Edat Mitjana. Organització institucional i construcció naval a la Corona d'Aragó (Barcelona: Museu Marítim de Barcelona. Angle Editorial, 2004), 19 y 167.

${ }^{3}$ Factura por la tala de árboles en Sant Cugat, Cerdanyola del Vallès y Barberà del Vallès para la construcción de naves (1650) CCAM 11/C.VII-22.06/11 Armades i ports-Armadas y puertos. ${ }^{4}$ Antoni Riera Melis, "La construcció naval a Catalunya a les vespres des grans descobriments geogràfics (1350-1450)," Universitat de Barcelona. Revista d'Historia Medieval, nº3 1(992): $55-78$.

${ }^{5}$ M. Teresa Ferrer Mallol, "El comerç català a la baixa edat mitjana," Catalan Historical Review, 5 (2012): 165.

${ }^{6}$ CCAM Pergaminos Municipales 01/ IA-70.

${ }^{7}$ Lezda de Mediona: CCAM 01/1A-5 y también 01/1G-010 Llibre verd vol1 fols 211r i v.

${ }^{8}$ Francesc Carreras Candi y Bartomeu Gunyalons Bou, Rúbriques de Bruniquer, Cerimonial dels magnifichs consellers i regiment de la ciutat de Barcelona (Barcelona: Impremta Henrich i cia., 1913) Vol.3 Cap. 50, 312 . En1357 las imposiciones eran dieciséis: Ganado, mantas, armas, aceite y productos vendidos según medidas, cuero, madera, peya, tejidos, honores, pesaje de la plata y de productos vendidos a peso, vino y vendimias, harina, carne y pescado fresco, cristal, cera, y yeso/cal.

${ }^{9}$ Francesc Carreras Candi y Bartomeu Gunyalons Bou, Op. Cit., Vol.3, Cap. 49, 299

${ }^{10}$ Pere Ortí Gost, "Les finances municipals de la Barcelona dels s. XIV i XV: Del censal a la Taula de canvi» Barcelona quaderns d'història,” [en línia], nº 13 (2007): 267 y 275.

${ }^{11} \mathrm{M}$. Teresa Ferrer Mallol, Op. Cit., 166.

${ }^{12}$ CCAM Pergaminos municipales 01/IA-356.

${ }^{13}$ Bans de la fusta. Dilluns, 20 de febrer, 1363. Ara hoiats, per manament del veguer ordonaren los consellers prohomes de la ciutat que tota persona de qualque condició sia qui compra o vena carratals, tirans, dobblers, maderos, caxes, tahuts, lits, coffrens, cabirons e tota altra fusta obrada e a obrar que sia tengut pagar bé e leyalment la ajuda que ordonada hi és. E qui contrafarà pagarà per ban XL sous. CCAM 03/1B.IV-1 Registre d'Ordinacions fol. 8r.

${ }^{14}$ Debemos aclarar que el término confraria es el término catalán para designar el concepto gremio. En Catalunya hasta 1714 las asociaciones de oficios recibieron el nombre de ofici, comú o confraria siendo introducido el término gremio con la aplicación del Decreto de Nueva Planta en 1714 .

${ }^{15}$ El privilegio dado por Jaume I en 1249 fue confirmado posteriormente por Pere III en 1284 con carácter irreversible, convirtiéndose en la base del derecho municipal de Barcelona.

${ }^{16}$ CCAM 01/1G-100 f. 8 r.

${ }^{17}$ En 1441,1442 y 1447.

${ }^{18}$ CCAM 1B.IV- 7 f. 44.

${ }^{19}$ CCAM Lletres closes 1B.VI-18 (1453-1455), fol. 110.

${ }^{20}$ CCAM Manuscritos municipales 01/1G-38 fol. 185 r.

${ }^{21}$ CCAM 02.04/2A.2 1490.

${ }^{22}$ También llamadas Voltes dels Boters o dels fusters.

${ }^{23}$ Montserrat Bajet i Royo, El Mostassaf de Barcelona i les seves funcions en el s. XVI. Edició del

"Llibre de les Ordinations" (Barcelona: Fundació Noguera,1994), 202- 203.

${ }^{24}$ Albert Estrada Rius, op.cit., 107- 110. 
${ }^{25}$ Alfredo Chamorro Esteban, "Mestres d'aixa i mestres calafats a la Barcelona del segle XVII: dos exemples de confraries marítimes a l'època moderna (1599-1648)," Drassana: revista del Museu Marítim de Barcelona, $\mathrm{n}^{\circ} 27$ (2019): 56- 89.

${ }^{26}$ El privilegio de constitución de la cofradía no forma parte de los fondos del AHCB. Consultar: Próspero Bofarull. Colección de Documentos inéditos del ACA Gremios y Cofradías de la antigua Corona de Aragón (Barcelona: Archivo de la Corona de Aragón) tomo 40 p. 353. Reg. 1002, fol. 56v. El privilegio está citado en el Manuscrito CCAM 01/1G-100.

${ }^{27}$ En 1309 la atarazana de la ciudad construyó una escuadra de 22 galeras contra el rei de Granada. Albert Estrada Rius, op. Cit pgs 165 y168.

${ }^{28}$ Requisitoria contra un carpintero que se hacía ayudar en su trabajo por cinco maestros de azuela (1817) 5D142/090.

${ }^{29}$ Aunque Aymar i Puig en su monografía sobre los carpinteros barceloneses afirma que en 1257 cuatro carpinteros formaban parte del Consell de Cent, no cita la fuente, por lo que consideramos 1318 como la fecha más temprana en la que se constata la existencia de una pseudo corporación de carpinteros no constituida todavía en cofradía. Llibre del Consell 02.01/ 1B.I-5 fol.2r. ${ }^{30} \mathrm{El}$ privilegio de 1388 no forma parte de los fondos del AHCB, pero sí el de 1393 otorgado por Joan d'Aragó a 15.12.1393 (5D142/093). Consultar también Próspero Bofarull. Op. cit. Privilegio de 1388: tomo 40 p. 323 Reg. 1393 fol 182r. y privilegio de 1393: tomo 41 p.88, Reg.1906 fol.192v. ${ }^{31}$ CCAM. Obreria 1C.XIV- C67/1802 Expediente tramitado por los prohombres y oficiales del gremio de Carpinteros para poner un mirador en el primer piso de la casa gremial que están reedificando.

${ }^{32}$ CCAM 03/1B.IV-7, f.24 (29.05.1434).

${ }^{33}$ Ver 5D142/011.

${ }^{34}$ CCAM 02.04/2A.1-C5 doc.25 “Trassa: arquimesas, pilars, columnes, portalades, coronisas, frontispicis, de biaix, y montea, sostres ab pasteras, ancavalladas y altres en les quals coses venen compreses tota especie d'arquitectura en fusta"

${ }^{35}$ CCAM 03/1B.IV-9 (1463- 1471).

${ }^{36}$ CCAM 03/1B.IV-10 fol 102 r. v. (1471- 81).

${ }^{37}$ Las Rúbriques de Bruniquer consignan numerosas entradas relativas a la construcción y mantenimiento de puentes de los portales y puertas de la ciudad: Portal de l'Àngel, Portal Nou, Portal de Mar y Sant Antoni. puertas de Jonqueres, Sant Pau, Tallers y Sant Daniel; puentes del llano de Barcelona: de la Llacuna,de la Verneda, de la Vall del testament dels ases y de la Sèquia Madriguera.

${ }^{38}$ Antònia M. Perelló Ferrer, L’Arquitectura civil del segle XVII a Barcelona. (Barcelona: Publicacions de l'Abadia de Montserrat, 1996), 83. Menciona a los carpinteros Riera y Aimeric. ${ }^{39}$ CCAM 02.01/1.B.II-159 Registre de Deliberacions (30.11.1649-30.11.1650).

${ }^{40}$ CCAM 02.04/2A.1-C5 doc.25 “...gúbies, enformadors, barlet, massa, sertas i aixas, adressador, garlopa, ribots, planas, bossells, copades, reganyador, guilleumes, escayres, nivells, cartabó, taulaplom i altres que omiteixen".

${ }^{41}$ Jesús Sancho "El puerto medieval de Barcelona, al descubierto," La Vanguardia, junio 1, 2020. Los últimos estudios arqueológicos hacen coincidir la construcción del primer muelle con la progresiva desaparición natural de las Tasques, que eran barreras de sedimentos aportados por el Besós, paralelas a la costa y que permitían a barcos de gran calado fondear en los canales que las separaban. Quizá por este motivo Barcelona no había construido ninguna estructura portuaria hasta mediados del s. XV. Riera, Miró y Julià. Pla Barcino. Servei Municipal d'Arqueologia de l'Ajuntament de Barcelona.

${ }^{42}$ CCAM 02.01/1B.II- 23 fols. 147 r- 154 r. Deliberaciones sobre la llegada del maestro Alexandrino para la construcción del muelle.

${ }^{43}$ CCAM 08/1B.XXV- 21.

${ }^{44}$ CCAM 02.01/1B.II- 151 fol. $71 \mathrm{v}$. 
${ }^{45}$ Albert Estrada Rius, Op. Cit p. 106 cita este tipo de cajas en los inventarios de la atarazana de Barcelona AHCB CCAM C.VII-22 f. suelto s.n.

${ }^{46}$ CCAM 02.01/1B.II-66.

${ }^{47}$ CCAM 01/ IA-377, IA-384 y IA-385.

${ }^{48}$ Francesc Carreras Candi y Bartomeu Gunyalons Bou, Op. Cit. Vol.2, Cap. 20, 49.

${ }^{49}$ Con ello (constitución del gremio) se desarraigará un considerable ramo de comercio exterior pasivo que promovía la extracción de crecidas sumas del reino y se reducirá a interior activo en este Público, de forma que sin depender en el particular de la república de Olanda [sic] como hasta el dia, logrará Barcelona surtir a toda esta provincia y propagar en ella unas manufacturas de igual consistencia y hermosura que las extrangeras [sic] y a mayor comodidad en su precio porque los géneros simples de que se fabrican no se han de mendigar a fuera y por lo mismo se evitan en las compras los precios muertos que antes las hacían más costosas. CCAM 2A.2 Cadiraires- Silleros doc. 1.

${ }^{50}$ Francesc Carreras Candi y Bartomeu Gunyalons Bou. Op. Cit. Vol.2 Cap. 22, 114.

${ }^{51}$ Josep M. Madurell i Marimón, "Los escultores de Barcelona y la fundación de su cofradía," Instituto Municipal de História. Divulgación histórica de Barcelona (1945).Vol.V, 209- 212.

${ }^{52}$ CCAM 02.04/2A.1-C5 docs. 21 y 24.

${ }^{53}$ CCAM 02.01/1.B. II- 10 y -11.

${ }^{54}$ CCAM 02.01/1.B. II-159 fols. 367 y 401.

${ }^{55} 1450,1487,1491,1503$ y 1505.

${ }^{56}$ AHCB3-582/5D144 Confraria dels Dauradors-Cofradía de Doradores (1703-1834) Leg.2 Ordenaciones dadas a pintores cortineros y retablistas (1519).

${ }^{57}$ CCAM 06.01/1B.XXII-3.2 Albaranes correspondientes a pintura y decoración de techos y paredes en la casa de la ciudad (1369-1372).

${ }^{58}$ CCAM 02.01/1.B.II-13 fols. 111 y 112.

${ }^{59}$ CCAM 02.01/1.B.II-173 (30.11.1663) fols. 1 y 7. Pintura mencionada por Laura Farías Muñoz, "La imagen política de Santa Madrona en la Barcelona del seiscientos," en Nuevas perspectivas de investigación en Historia Moderna: economía, sociedad, política y cultura en el mundo hispánico, editado por $\mathrm{M}^{\mathrm{a}}$ Ángeles Pérez Samper y José L. Betrán Moya (Barcelona: Universitat de Barcelona, 2018), 928.

${ }^{60}$ CCAM 02.01/1.B.II-90 f.131v.

${ }^{61}$ CCAM 01/1G-100.

${ }^{62}$ CCAM 02.01/1.B.II-159 fols 84 y 91.

${ }^{63}$ CCAM 02.01/1.B.II-156 (13.11.1647).

${ }^{64}$ AHCB2-421/FI-08.4/ 1-18 Bartomeu Joan 1495.

${ }^{65}$ En el sentido de grupo musical compuesto de cantores e instrumentistas dirigidos por un maestro de capilla al servicio de una institución religiosa, nobiliaria o civil.

${ }^{66}$ 02.01/1.B.II-179 f. 171r. y v. 